\title{
AN APPROXIMATE COST-INTEGRATED MODELLING APPROACH TO CROSS DOCK DESIGN
}

\author{
Antonio G.N. Novaes ${ }^{1 *}$, Edson T. Bez ${ }^{2}$ and Daniel D. Adriano ${ }^{2}$
}

Received September 22, 2016 / Accepted March 8, 2017

\begin{abstract}
Cross docking is a form of operating break-bulk freight terminals in which the receiving products are not stocked but, instead, the incoming cargo is internally transferred to be immediately shipped in distribution trucks. With this approach, inventory costs and lead-times are significantly reduced. In this work, an approximate, continuous, non-stationary queueing model is established to estimate the number of cargo discharging doors in the receiving dock. Since the traditional first-come, first-served queueing discipline is not applicable to this specific problem, an alternative formulation, called least-distance, firstserved queue discipline, is adopted and analysed with a simulation approach. The problem is modelled to support a preliminary design of a cross-dock terminal. The objective function, to be minimized, is the sum of the rent cost of the terminal facility, the waiting cost of inbound trailers when being attended at the terminal, and the cost of handling and moving freight inside the terminal.
\end{abstract}

Keywords: cross-docking, approximate queue modelling, simulation, door assignment, truck scheduling.

\section{INTRODUCTION}

Freight terminals, in the less-than-truckload (LTL) transport industry, are facilities in which shipments are unloaded, checked, sorted, consolidated, and ultimately loaded into outgoing trailers for delivery elsewhere in the supply chain. In addition to being costly, freight handling is important because the time that a shipment spends at the terminal is wasted in the sense that the shipment is not making progress toward its final destination (Gue, 1999). A special freight terminal operation is cross docking, a logistics strategy used by companies in different industries for transferring incoming product shipments directly to outgoing vehicles without significantly storing goods in between. Inbound trailers or trucks bring products from suppliers, which are unloaded, moved across the terminal and finally loaded into outbound trucks, which immediately

\footnotetext{
*Corresponding author.

${ }^{1}$ Departamento de Engenharia de Produção, Universidade Federal de Santa Catarina - UFSC, 88040-900 Florianópolis, SC, Brasil. E-mail: antonio.novaes@ufsc.br

2Universidade do Vale do Itajaí - Univali, 88302-901 Itajaí, SC, Brasil.

E-mails: edsonbez@gmail.com; daniel.dadriano@gmail.com
} 
leave the terminal to deliver the cargo to their ultimate destinations in the distribution network (Boysen \& Fliedner, 2010). This practice has a number of objectives: the consolidation of shipments from diverse suppliers, the shortening of delivery lead-time, reducing inventory and order picking costs, etc. (Boysen \& Fliedner, 2010; Van Belle et al., 2012; Buijs et al., 2014). In contrast to a traditional warehouse, the storage of goods is reduced to the greatest possible extent. As a result, the cross docking approach enables the consolidation of many less-than-truckload (LTL) shipments between multiple shippers and recipients, thus generating economies of transportation and inventory. Consequently, hub-and-spoke distribution networks, replacing traditional pointto-point deliveries, have been made possible (Stephan \& Boysen, 2011). But handling freight in an LTL terminal is labour intensive and therefore expensive, since workers must quickly sort and move a variety of freight. An important way to reduce such work is to assign inbound trailers and outgoing trucks to rationally chosen doors of the terminal to take advantage of patterns of freight flows (Bartholdi \& Gue, 2004).

As stated, the crossdocking terminal is a special type of warehouse. A traditional warehouse has four basic functions: cargo receiving, storage, order-picking and shipping. First, a bundle of freight is received at a warehouse, and then placed in a storage location. Next, order-picking occurs when an item is requested by a customer. Finally, shipping is activated when orders are consolidated and moved to trailers. Among all activities, storage and order picking together account for about $70 \%$ of warehouse operation expenses (Bartholdi \& Hackman, 2014). The crossdocking system, like the just-in-time (JIT) system, is designed to reduce inventory and labour processing, and also aims to attain transportation economies within shorter order cycle times. Crossdocking attains these benefits by transferring shipments directly from inbound trailers to outbound trailers with minimum storage in between. Usually, cargo is shipped within 24 hours, though sometimes it could be less (Apte \& Viswanathan, 2000).

Typically, a small or medium cross-docking terminal is composed of a rectangular open-area building with several dock doors located around its perimeter (Fig. 1). Other terminal layouts and formats, with X, L, T shapes, as well as some other forms, are also encountered in the real world and analyzed in the literature (Bartholdi \& Gue, 2004, Van Belle et al., 2012), but the rectangular shape is predominant. Part of the dock doors is assigned to inbound trucks that bring freight to be unloaded. Another group of doors is reserved to outbound trucks, which will perform the immediate delivery of products to their destinations. Inbound vehicles are usually of a trailer type, whereas outbound vehicles are mostly trucks. But both terms are indifferently used for both situations in this text. The two dock door types are named strip doors, where trailers are attached to the dock to be unloaded, and stack doors, where outbound trucks are located to be subsequently loaded (Gue, 1999). A vehicle in a stack door receives freight for a same destination, or for a pre-defined group of destinations (for example, a group of stores in a supermarket chain), regardless of their origins or contents (Bartholdi \& Gue, 2000).

When an inbound truck arrives at a cross dock terminal and all of the strip doors are occupied, it is assigned to a queue position on a parking place in order to wait to be served (Fig. 1). At due time, the vehicle is commanded to approach a strip door to start the cargo unloading process. 
When the unloading process is under way, the cargo shipment is registered, checked, and sorted according to its destinations. Next, the cargo is moved inside the terminal with manual fourwheeled platform dollies, pallet jacks, forklift movers, or other material handling equipment, whose selection depends on the cargo characteristics and volume, up to a temporary staging area close to the respective shipping dock door. At this place, other services, such as labelling and addressing may be executed while the cargo waits to be loaded into the outbound trucks. As soon as an outbound vehicle is ready, it leaves the terminal to its final destinations (Stephan \& Boysen, 2011).
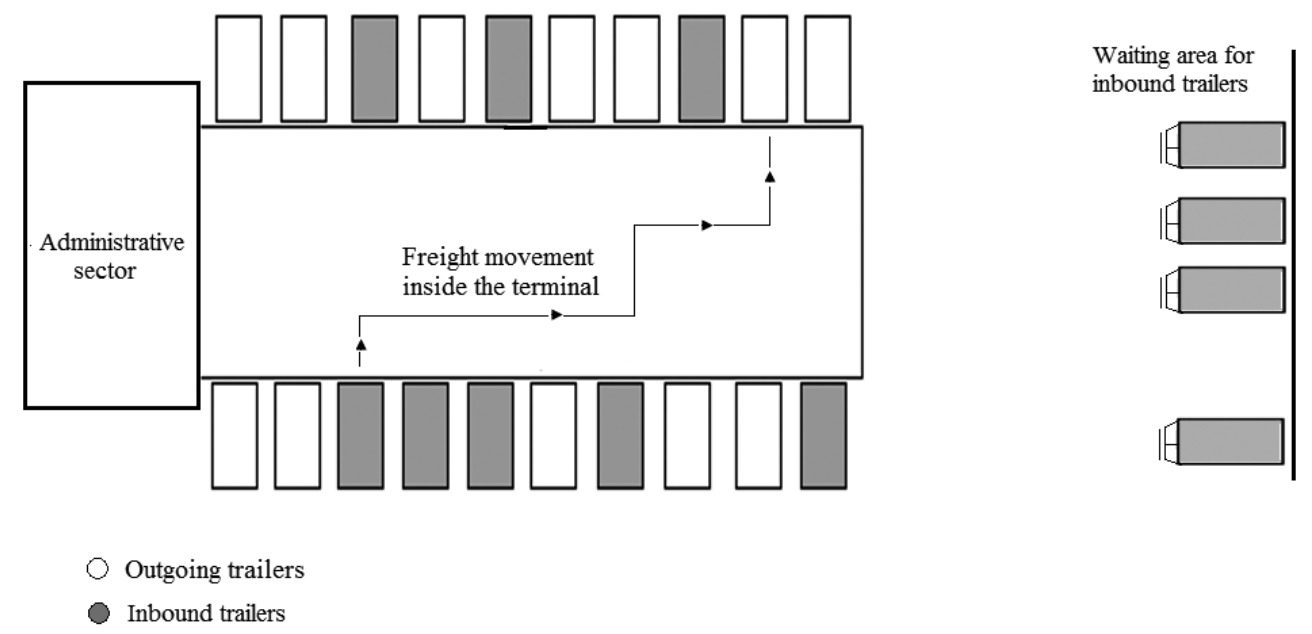

Figure 1 - A typical rectangular cross dock terminal.

In this paper, an approximate, continuous, non-stationary queueing model (Newell, 1971) is established to estimate the number of cargo discharging doors in the receiving dock. Since the traditional first-come, first-served queueing discipline is not applicable to this specific kind of problem, an alternative formulation, called least-distance, first-served queue discipline, is adopted and analysed with a simulation approach. The objective function, to be minimized, is the sum of the rent cost of the terminal facility, the waiting cost of inbound trailers when being attended at the terminal, and the cost of handling and moving freight inside the terminal. The internal transport of cargo is alternatively performed with four-wheel platform dollies, or with electric pallet trucks. The problem is modelled to support a preliminary design of a cross-dock terminal.

\section{LITERATURE REVIEW AND MOTIVATION}

A great number of research work on cross docking is concerned with dock door assignment problems (Van Belle et al., 2012). It is because dock door assignment deeply affects the material flow and the freight carrying costs inside the facility. But, regarding truck scheduling problems, reported applications generally assume that either all inbound vehicles are present at the cross- 
dock facility at the beginning of a working period, or the time each truck arrives at the cross-dock facility is known in advance (Sadykov, 2009; Vahdani et al., 2010; Alpan et al. 2011; Konur \& Golias, 2013; Van Belle et al., 2013). However, the assumption that truck arrival times are known beforehand with certainty is unrealistic, as truck arrivals are subject to uncertainties due to delays at the suppliers' premises, traffic congestions, weather conditions, or maintenance drawbacks (Boysen \& Fliedner, 2010; Konur \& Golias, 2013). As a consequence, current applications generally cover the problem only partially, reflecting realistic situations and maintaining the analysis restricted to some specific aspects, usually on the operational decision level (Agustina et al., 2010). Instead, the research work object of this paper assumes a tactical decision framework, with the objective of producing robust results, albeit approximate, to support a preliminary design of a cross dock terminal (Berghman \& Leus, 2015). Such a preliminary design is normally intended to cover a gap between a general design conception and the ultimate detailed design, particularly when the level of initial conceptualization is not sufficient for a full evaluation of the project, mainly in economic terms. Approximate modelling is thus employed, covering the essential parts of the problem, as dock door assignment, truck scheduling and waiting time, as well as an integrated minimal cost formulation. In Brazil, although no specific works on crossdocking are available in the local OR literature, some articles cover related subjects, as integrated production and distribution problems (Reimann et al., 2014), and logistics cargo terminals (Vieira \& Luna, 2016).

In general, three extensively cited papers in the literature present a good review of cross docking research: Agustina et al. (2010), Boysen \& Fliedner (2010), and Van Belle et al. (2012). The reviews are quite ample and provide a classification analysis of the most important problems encountered in the literature on cross docking modelling and applications. Diverse types of problems, covering strategic and tactical decision approaches are described and analysed, such as location of cross dock terminals, cross docking networks, facility layout design, as well as operational problems such as vehicle routing, dock door assignment, truck scheduling, and temporary storage (Van Belle et al., 2012). However, a large number of papers are not directly related to our work, and therefore will not be referred here. Readers interested in a more general review of the problem shall consult Agustina et al. (2010), Boysen \& Fliedner (2010), and Van Belle et al. (2012).

\subsection{Inbound trailer waiting time}

Queue modelling is a traditional branch of operational research, with reported application areas being healthcare, transport, and telecommunications, among others (Worthington, 2009). It involves analytical investigation of processes that lead to people, or other element, to wait before starting to be served. Its objective is to determine and analyse performance measures, which express the efficiency and effectiveness of these processes. Among those measures are: expected number of elements in the queue, average waiting time to be served, idle time of service providers, etc. (Fogliatti \& Mattos, 2007). The average queue size and the time a truck spends in a queue waiting to be served is usually estimated with a mathematical queueing model 
conveyed in basic texts such as Prabhu, 1965; Page, 1972; Gross et al., 1985; Fogliatti \& Mattos, 2007. A more recent review on queue modelling is presented by Worthington (2009).

Mathematical queue modelling is usually based on Markov Chains (Fogliatti \& Mattos, 2007). The queue, when is ergodic, converges to a stochastic equilibrium situation called a stationary state, in which state probabilities are independent of time (Fogliatti \& Mattos, 2007). Such classical models, however, usually do not apply to the analysis of queues formed by incoming trucks to be unloaded at cross-docking facilities. In fact, in most cross-docking terminals the queueing process does not reach a stationary state. Three main reasons support this statement. First, cross dock terminals are usually operated within pre-defined time windows. A trailer arrives at a random time $t$ respecting the time window $t_{0} \leq t \leq t_{E}$ established by the terminal management, and within this time interval there is no guarantee that the stationary state will be attained. Second, the truck arrival rate may vary substantially over the time-window period, a situation quite different from the classic theoretical approach, in which the average arrival rate is constant. Finally, when the receiving strip doors are closed at time $t_{E}$, although no additional incoming trailers are allowed, the unloading process may continue for a while in order to serve the vehicles still in the queue.

An interesting approximate approach to queueing investigation is due to Gordon F. Newell (1971), who developed a methodology to analyse non-stationary queues with simple, straightforward techniques, under a continuous approximation approach. Whereas most of the literature on queues deals with equilibrium distributions of queue lengths and waiting times, the main emphasis of the Newell's approach is on time-dependent behaviour, as in this paper, where the arrival rate of users changes along time. The techniques employed by Newell (1971) are mainly fluid and diffusion approximations. Much of the classical theory of queues deals with discrete models, but in simple continuous approximations such as Newell's, it is convenient to initially disregard the discrete nature of some elements, treat them as continuous or quasi-continuous variables, and return back to the discrete representation afterwards.

Another approach to queue modelling is simulation (Worthington, 2009). Today, due to advanced commercial simulation software, associated with technological evolution in computational techniques, many queue modelling applications make use of simulation models. A good number of papers using simulation techniques to solve cross dock operational problems are presented in the literature (McWilliams et al., 2005; Deshpande et al., 2007; Liu \& Tatakuwa, 2010; Takakuwa et al., 2010; Shi et al., 2013). Such a technique will be partially used in this work because the traditional First-Come, First Served (FCFS) queue discipline assumed in Newell's (1971) approach is not adequate to represent the priority scheme of attending incoming trailers to be unloaded at strip doors (see Section 3.3).

\subsection{Dock door assignment}

Efficient operation of a cross-dock system requires an appropriate coordination of inbound and outbound flows. In fact, a substantial part of the cross-dock operating cost is due to the intense 
movement of workers and material handling equipment across the facility, when freight is transferred from incoming to outgoing trailers, and this operation is expensive (Gue, 1999). As a response to this, quite a number of quantitative modelling approaches have been developed and applied with the objective of defining adequate terminal layouts, in which one searches for the best arrangement of strip doors and stack doors (Gue, 1999; Miao et al., 2009, 2014; Boysen \& Fliedner, 2010; Vis \& Roodbergen, 2011; Acar et al., 2012; Gelareh et al., 2016).

When an inbound trailer arrives at the cross dock terminal, it is necessary to decide to which strip door the vehicle should be assigned. On the other hand, outbound trucks must be assigned to stack doors. Thus, the dock door assignment problem aims to find the optimal positioning of strip and stack doors along the facility perimeter, with the objective of minimizing freight handling and displacement costs (Van Belle et al., 2012). A good door assignment can increase the productivity of the terminal and decrease the internal handling costs.

In some cases, as in this work, the assignment of outbound trucks to stack doors is executed on a mid-term horizon, with the result that each stack door will exclusively serve a specific outbound destination (or group of destinations) for a somewhat longer period of time (a month, or a season, for example). Such a fixed assignment eases the allocation of shipments to the outbound trucks, consequently yielding a learning effect on workers' movements. Such a fixed stack door assignment to outbound trailers is especially suited for steady commodity flows, with reliable distribution of cargo among inbound flows and outbound destinations (Boysen \& Fliedner, 2010), as in the case of this application. Thus, on a typical working day, each outbound truck is assigned to a previously determined stack door, and this setting pattern is maintained during a somewhat long period of time (Van Belle et al., 2012).

Two recent reviews of dock door assignment are due to Van Belle (2012) and Acar et al. (2012). An early and extensively cited study about the assignment of dock doors was presented by Tsui \& Chang (1992). They formulated the door assignment problem with the objective of minimizing the total distance travelled to move freight inside the facility. Bozer \& Carlo (2008) formulated the door assignment problem as a mixed integer programming model with the objective of minimizing material handling cost. Simulated Annealing was also used to solve the proposed model, taking into consideration congestion and robustness.

Cohen \& Keren (2009) also extended the approach by Tsui \& Chang (1992). The mathematical model was adapted to allow that freight, for a certain destination, can be split and delivered to multiple doors assigned to that destination (the capacity of the outbound trucks is taken into account). The proposed formulation is a non-linear MIP model that is impractical for real size problems. So, the authors proposed a heuristic algorithm to solve it. Acar et al. (2012) proposed a robust door assignment method focussing operational uncertainties in LTL operations. Time variability associated with vehicle arrival and service time is treated in the model acting on the idle time subsequent to each truck unloading service. 


\subsection{Truck scheduling}

In a truck scheduling problem, the goal is to determine the assignment of incoming vehicles to strip doors, and outbound ones to stack doors (Agustina et al., 2014). It is worth mentioning that the truck scheduling problem is different from the strict dock-door assignment problem. In particular, the truck scheduling problem takes time dimension into account, while time is not explicitly considered in the dock door assignment problem (Van Belle et al., 2012; Konur \& Golias, 2013; Amini et al., 2014, 2016). As noted by Boysen \& Fliedner (2010), door environment (dock assignments, number of doors, mixed doors) and operational characteristics such as truck arrivals, preemptions, shipment deadlines, vehicle waiting time, and storage restrictions, affect truck scheduling at cross-dock facilities. Furthermore, it is noted that the objectives are mainly time related such as minimization of makespan, total service times, and tardiness.

McWilliams et al. (2005), Yu \& Egbelu (2008), Maknoon \& Baptiste (2009), Boysen et al. (2010), and Shakeri et al. (2012) assume that truck arrival times are identical and equal to zero i.e., all trucks are available at the beginning of the planning period. Sadykov (2009), Vahdani et al. (2010), and Alpan et al. (2011), on the other hand, assume that truck arrival times are given. However, assuming truck arrival times are known with certainty is unrealistic as truck arrivals are subject to delays at the suppliers' premises, uncertainties due to traffic congestions, variable weather conditions, or truck failures (Boysen \& Fliedner, 2010). These assumptions, therefore, may result in suboptimal scheduling strategies in practice (Boysen \& Fliedner, 2010), and affect cross-docking efficiency as waiting and delivery times heavily depend on the scheduling strategies (Wang \& Regan, 2008). In a more recent review of cross-docking studies, Van Belle et al. (2013) note that the assumption of deterministic arrival times is a shortcoming of the truck scheduling studies encountered in the literature. One important feature of this paper is to admit random arrivals of incoming trucks (Section 3.4), therefore overcoming this kind of restriction and making the analysis more realistic.

Van Belle et al. (2012) divide the research works about the truck scheduling problem in three categories. A first category considers a simplified cross dock pattern with a single strip and a single stack door. Truck scheduling reduces, in this case, to sequencing the inbound and outbound trucks. The works in the second category consider cross docks with multiple strip and stack doors, but deal only with the scheduling of inbound trucks. The last category is related to papers that consider both inbound and outbound truck scheduling at multiple dock doors. The truck scheduling problem investigated in this paper belongs to the second category. The objective is to minimize the sum of three costs, namely the real estate cost of the facility, the waiting cost of inbound trucks before being unloaded at the dock, and the cost of handling and moving freight inside the terminal (Section 4.2).

\subsection{Terminal layout}

A strategic decision that has to be taken when starting a cross dock design is to choose its layout pattern. The layout is interpreted as the dimension and shape of the cross dock building, as well as 
the dimension and shape of the internal cross dock areas and their arrangement (Van Belle et al., 2012; Vis \& Roodbergen, 2001). The layout problem of a cross dock terminal was investigated by Bartholdi \& Gue (2004). In the analysis, the best shape of the terminal building (e.g., I, T, $\mathrm{E}$, or X-shaped facilities) and the location of strip and stack doors are determined (Boysen \& Fliedner, 2010). In practice, most of existing cross docks are long, narrow rectangles (I-shaped). Several experiments are reported in the literature in which the labour cost (estimated via the total internal travel distance) was measured for different shapes. The experiments suggested that an I-shape is the most efficient pattern for smaller cross-docks (fewer than about 150 dock doors). For docks of intermediate size, a T-shape is best, and for more than approximately 200 doors, an $\mathrm{X}$-shape is best (Van Belle et al., 2012).

The layout of the terminal influences internal freight carrying costs in three ways. First, as the number of dock doors raises, the average distance between strip and stack doors also tends to increase, with parallel effect on freight handling costs. Second, workers are more productive when inbound trucks are nearer to the appropriate destination trucks, because this reduces travel distance and internal traffic conflicts. Thus, it is advised to assign incoming trailers to strip doors close to the destination vehicles for which they have the most freight. Third, the shape of the terminal (e.g. rectangular, I, T, X-shaped, etc.), as mentioned, also influences freight handling costs. In addition to internal travel distances, Bartholdi \& Gue (2000) introduced the congestion cost due to different types of traffic conflicts. Although of interest, most of the current published research on the subject takes into account just the internal travelling distance, taking this element as a proxy variable used to estimate the total cost of transferring freight from the strip doors to the shipping docks. In this paper, this approximation is also assumed.

\section{PROBLEM FORMULATION}

The problem studied in this paper belongs to the second category of truck scheduling analysis as indicated in Section 2.3, and considers a cross dock with multiple strip and stack doors, but dealing only with the scheduling of inbound trailers (Van Belle et al., 2012). In this case, the assignment of outbound trucks to stack doors is fixed for a somewhat long period of time (a month, or a season, for example), as indicated in Section 2.3. The objective function is the sum of three cost components: (a) the rent cost of the terminal building facility, which is related to its area and layout; (b) the waiting cost of inbound trucks when being attended at the terminal, and (c) the cost of handling and moving freight inside the terminal. These three costs are deeply interrelated, and must be analysed in an integrated way during the preliminary design phase of a cross docking facility (Rouwenhorst et al., 2000). The costs related to outbound trucks are considered fixed in our problem and therefore do not influence the search for the minimum terminal cost configuration.

The contributions of this paper are: (a) to develop a modelling framework of cross-docking basic operations in a simple and integrated way, involving different parts of the problem which have been treated separately in the literature; and (b) offering a simple, albeit robust, modelling 
approach that will allow researchers and practitioners to analyse prospective terminal configurations and compare alternative possibilities related to performance and costs. The basic assumptions of the truck scheduling problem are as follows (this listing is partially based on Van Belle et al., 2013):

- An exclusive mode of service is considered, i.e. each dock door is either exclusively assigned to inbound or to outbound trucks;

- A rectangular (I shaped) terminal is assumed (Bartholdi \& Gue, 2004), with strip and stack doors assigned to either side of the facility (Fig. 1);

- Arriving goods are unloaded from the inbound trailers and transferred to the appropriate outbound dock where they are ultimately loaded into outbound trucks. Other internal operations (like sorting and labelling) are not considered here;

- Preemption of loading or unloading a truck is not allowed. Thus, a docked vehicle has to be completely processed before it leaves the dock;

- Inbound trailers arrive randomly at the terminal, with arrival times following a known probability distribution (see Section 3.4);

- Departure times of outbound trucks are established by terminal supervisors and are not included as decision variables in the model;

- Freight is received in standardized cartons at the terminal;

- Two alternative internal transport modes are considered: (I) freight in cartons, carried in four-wheeled platform dollies (Section 4.2.3-A); (II) cargo in pallets, with freight palletized upon reception at the terminal and carried by pallet trucks (Section 4.3.3-B);

- The time needed (and the corresponding cost) to transfer freight from strip to stack doors is assumed to be directly proportional to the rectangular distance between the dock doors to which vehicles are assigned;

- Intermediated storage inside the terminal is partially allowed. This means that goods can be unloaded from an inbound trailer before the appropriate outbound truck is available. The capacity of the storage is considered infinite;

- The trailer changeover time is considered nil in the model;

- Products are not interchangeable, i.e. any arriving product unit is assigned to a specific outbound truck;

- The sequence in which goods are loaded or unloaded is not taken into account;

- The problem consists of $n_{V}$ inbound trailers, $m_{1}$ strip doors, and $m_{2}$ freight destinations. The main decision variable in the model is the number of strip doors. 


\subsection{Generating freight flows}

In practice, for small and intermediate size cross-dock terminals, supervisors usually tend to assign inbound trailers to strip doors without explicit regard to the destinations of the freight, since usually they adopt the FCFS priority rule to unload the vehicles (Gue, 1999). Among other reasons to do so, they do not have a decision support system to help them in making better assignments, in which the average travelled distance within the facility is minimized, for instance.

Workers are more productive when incoming trailers are nearer the appropriate outbound trucks, because this situation decreases internal travel distances and consequently reduces labour costs. Thus, it is advised to assign incoming trailers to strip doors close to the destination trucks that will take the most freight (Gue, 1999). But, since inbound trailers usually carry different cargo mixes to different destinations, it is difficult for the supervisor to individually decide to which vacant strip door he will assign a loaded trailer without the support of a more elaborate evaluation methodology. Specially, when the average number of destinations per incoming trailer is low, and the dispersion of destinations varies significantly per incoming cargo load, the optimized assignment of strip doors based on cargo flow and internal distance can lead to significant savings in material handling costs within the terminal (Gue, 1999).

Real data on the mix of freight per inbound vehicle and per destination is hard to obtain in Brazil, due in part to proprietary reasons, but also because they are not collected and organized in a way as to allow their utilization in this kind of research. In addition, logistics operators in the LTL industry do not record the size of individual cargo segments within a shipment (Gue, 1999). Thus, and following Bartholdi \& Gue (2004), empirical arrangements of freight flows carried by inbound trailers had to be specially generated through a Monte Carlo experiment, in order to supply quasi realistic data for modelling the problem. Freight is assumed to be transported in cartons. Specifically, in order to guarantee that the Monte Carlo generated configurations will show a relative low number of destinations per incoming trailer, as well as to have larger dispersion of destinations per vehicle as recommended by Bartholdi \& Gue (2004), a specific Monte Carlo algorithm was developed to generate random loads of freight for the incoming trailers, which satisfy these requisites.

Since cargo is not palletized at the origin in this case, and usually is not loaded in carton units either, an intermediate situation was assumed, in which the trailers are loaded at the supplier's premises in carton packs of 20 units each. Since each destination receives different amounts of products, it was assumed that the relative quantity of freight sent to each destination would follow a negative exponential function, as in Bartholdi \& Gue (2004)

$$
f_{j}=\left(f_{\max }-f_{\min }\right) \exp \left(-c_{f} \frac{j}{m_{2}}\right)+f_{\min }, \quad \text { with } \quad j=1,2, \ldots, m_{2},
$$

where $f_{j}$ is the fraction of the total flow of freight that goes to destination $j, f_{\max }$ and $f_{\min }$ are the maximum and minimum values of $f_{j}$ respectively, $c_{f}$ is a constant, and $m_{2}$ is the number of destinations. Destinations are classified into a decreasing order of cargo flow magnitude. 
Selecting appropriate values for $f_{\max }, f_{\min }$, and $c_{f}$ and applying function (1) to the total daily flow of freight, one has the average distribution of cargo per destination as depicted in Figure 2.

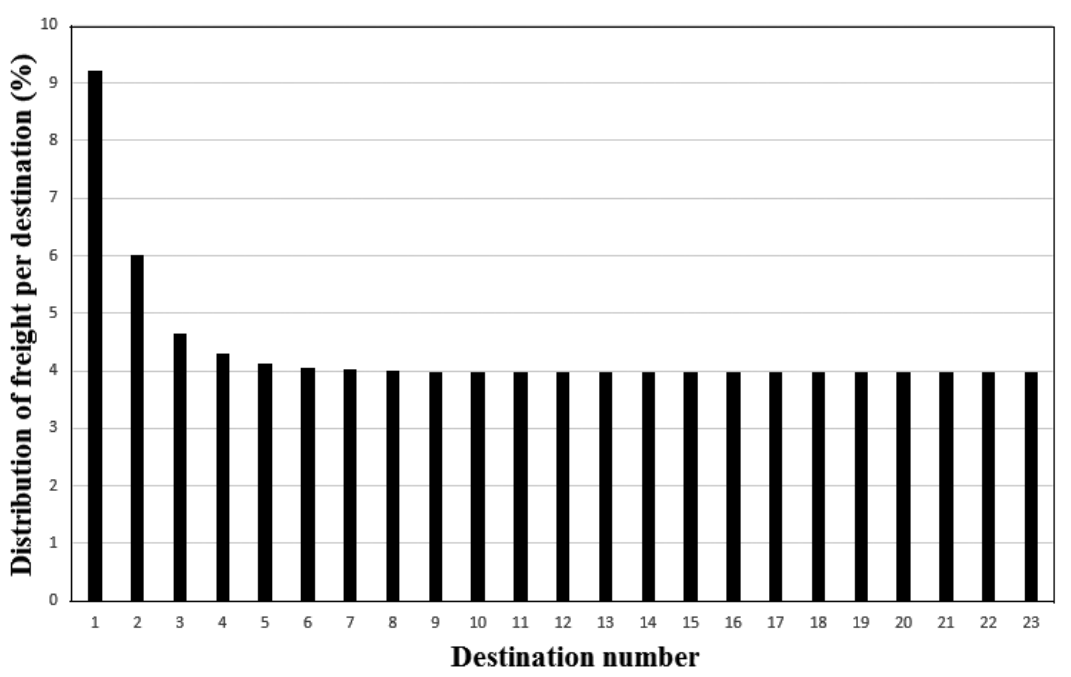

Figure 2 - Distribution of expected freight flow per destination.

The pseudocode of the Monte Carlo routine, intended to generate random freight loads for inbound trailers, is presented in Figure 3. The Monte Carlo algorithm generates trailer loads, forming vectors $V_{k, j}$, that express the freight flows (in cartons) carried by inbound trailer $k(k=$ $\left.1,2, \ldots, n_{v}\right)$ to destinations $j\left(j=1,2, \ldots, m_{2}\right)$, via the cross-docking terminal. It is assumed in the analysis a uniform fleet of trailers, each one with a capacity of $C_{T}$ cartons. Then, the Monte Carlo flow generating algorithm must respect the following constraint

$$
\sum_{j=1}^{m_{2}} V_{k, j}=C_{T}, \quad \text { for } k=1,2, \ldots, n_{v},
$$

meaning that all inbound trailers have a capacity $C_{T}$ and travel fully loaded. On the other hand, the total daily freight load $\emptyset_{j}$ designated to destination $j$, and containing cargo from all origins, is

$$
\emptyset_{j}=\sum_{k=1}^{n_{V}} V_{k, j}=f_{j} G, \quad \text { for } j=1,2, \ldots, m_{2},
$$

where $G$ is the total quantity of freight received at the terminal during the period $\left\{t_{0}, t_{E}\right\}$, in a typical working day. Since the Monte Carlo algorithm works sequentially, extracting random carton packs from a virtual inventory to be loaded into a trailer, the resulting load configurations are not necessarily independent in statistical terms. Therefore, and in order to avoid biased flow arrangements in terms of destinations and cargo quantities, the resulting load vectors $V_{k, j}$ are randomly sorted according to variable $k\left(k=1,2, \ldots, n_{v}\right)$ at the end of the Monte Carlo routine. During a typical working day, each destination $j$ receives a total of $\emptyset_{j}$ cartons, according to the proportions shown in (1) and in Figure 2. The Monte Carlo algorithm (Fig. 3) is composed of 
two stages. The first one is a greedy routine that tries to insert a larger number of carton packs into the vehicle, per operation. But, closer to the end of the loading process, the possible combinations of carton packs remaining in the virtual stock and ready to be loaded into a trailer, might be reduced to a fewer combinations. At this point, the search for an adequate random number of packs to fit the remaining space in the trailer might take too long a time. Thus, a complementary step-by-step loading routine will insert one carton pack at a time into the trailer, by varying the destinations until all the cargo is completely loaded. Thus, cargo arrangements that eventually remained incomplete at the end of the first stage, will be fully loaded at the end of the one-by-one unit stage.

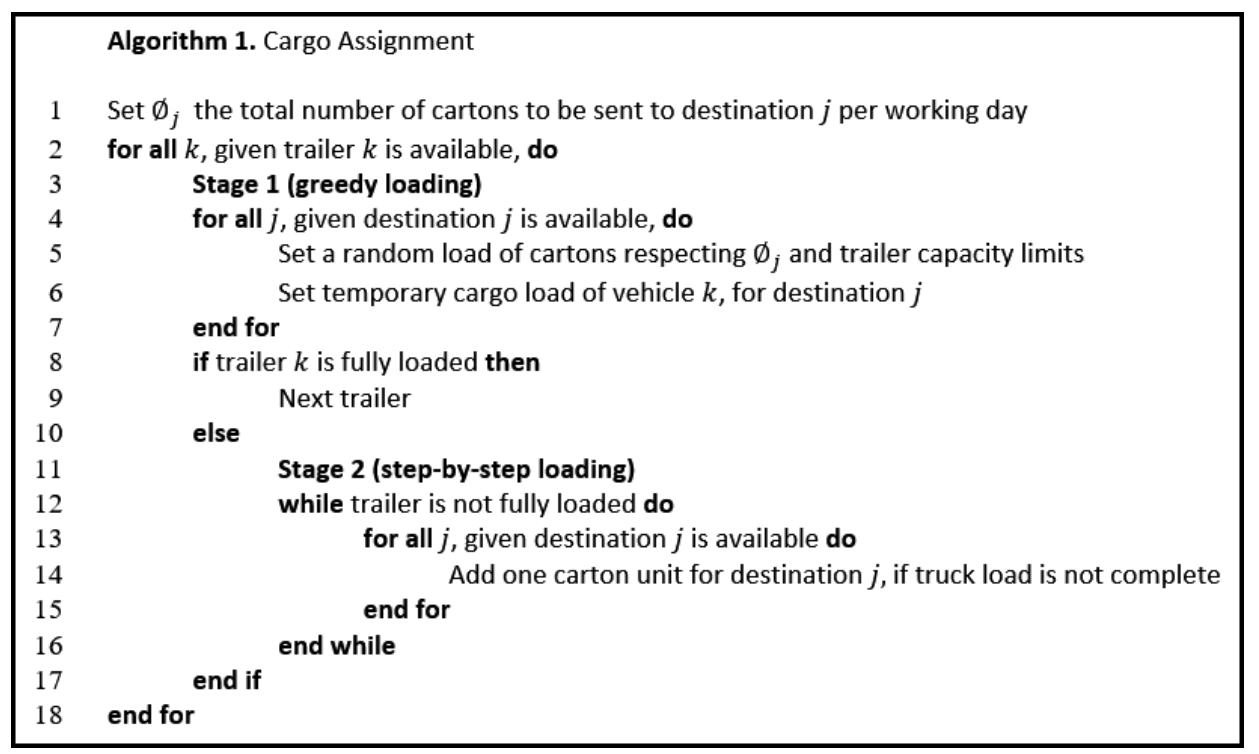

Figure 3 - Pseudocode of the Monte Carlo routine to generate random freight loads for inbound trailers.

Figure 4 shows two Monte Carlo generated trailer load configurations, each trailer having a capacity of $C_{T}=1,400$ cartons. Configuration (a), in Figure 4, depicts freight assigned to 9 destinations, a number about $39 \%$ of the total number of destinations. One can see a significant variation of cargo volumes per destination in Figure 4a, although the dispersion among destinations is not very expressive in this case. Conversely, there are less destinations in Figure 4b (7 destinations, about $30 \%$ of the total), but more dispersed than in the other configuration.

\subsection{Door assignment}

Most small cross docks are I-shaped because this type of layout offers the chance to move freight directly across the dock from a strip door to a stack door. But, in general, the assignment of strip and stack doors along the terminal perimeter is mostly based on getting the least average distance among all the doors on the dock (Bartholdi \& Gue, 2004). It is easy to see by this measure that doors in the centre of an I-shaped dock are the most convenient, and this measure of convenience 
decreases from the centre doors to the doors at each end of the dock (Bartholdi \& Gue, 2004). In practice, an approximate evaluation criterion is to consider the door with the smallest average distance to all other doors as the "best door", because it is the one to/from which a freight lot can be expected to move internally with the least travel distance.

Following Barthold \& Gue (2004), let

$n_{V}=$ number of inbound trailers per working day;

$m_{1}=$ number of strip doors;

$m_{2}=$ number of stack doors (equal to the number of destinations);

$i=$ a strip door, $i=1,2, \ldots, m_{1}$;

$j=$ the destinations to which the freight loads $V_{k, j}$, with $k=1,2, \ldots, n_{V}$ and $j=1,2, \ldots$, $m_{2}$, are assigned to;

$d_{i, j}=$ the rectangular distance from strip door $i$ to stack door $j$;

$C_{T}=$ cargo capacity of one inbound trailer (in cartons);

$\emptyset_{j}=$ total quantity of freight sent to destination $j$, in cartons per working day (3).

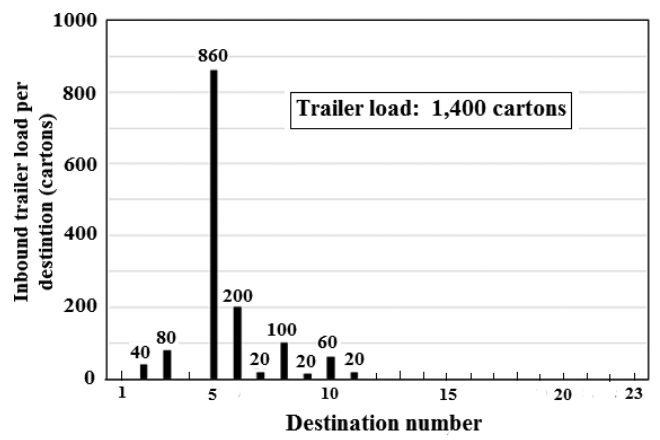

(a)

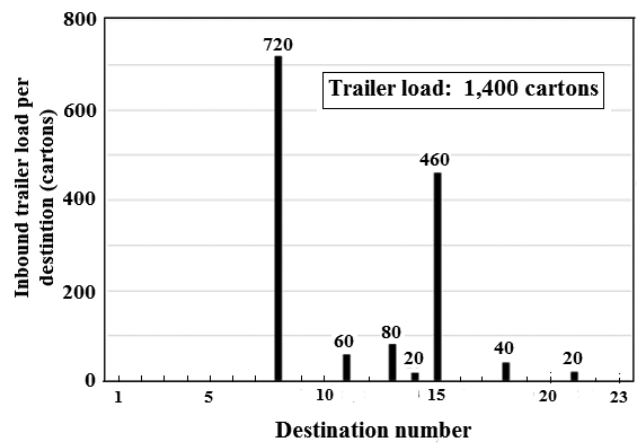

(b)

Figure 4 - Empirical Monte Carlo inbound trailer load configurations.

According to Bartholdi \& Gue (2004), the objective is to minimize the internal average travelled distance weighted by the freight volume

$$
\operatorname{Minimize} \bar{d}=\frac{\sum_{i=1}^{m_{1}} \sum_{j=1}^{m_{2}} \emptyset_{j} \times d_{i, j}}{\sum_{j=1}^{m_{2}} \emptyset_{j}} .
$$

The average distance $\bar{d}$ is assumed to be an approximation of the total internal travel cost across the dock, and therefore a proxy estimate of the variable labour cost to move freight through the facility (Bartholdi \& Gue, 2000, 2004). The optimization problem (4) is a combinatorial problem with the following formulation: (a) from the total of $m_{1}+m_{2}$ available dock doors, select $m_{1}$ doors to be used as strip doors according to some appropriate criterion, and $m_{2}$ doors to be stack doors; (b) assign each one of the $m_{2}$ stack doors to a specific destination. Strip doors, on the other hand, are assigned to inbound trailers along the working day according to the queue discipline and other factors, not having a specific identification related to freight origin, or other. 
In the literature, this type of problem, with a number of variations, has been solved with a mathematical integer programming model, a genetic algorithm formulation, a simulated annealing approach, or other (Agustina et al., 2010; Van Belle et al., 2012). Depending on the total number of dock doors, the problem can be somewhat difficult to solve in mathematical terms. Bartholdi \& Gue (2004) propose an approximate computational heuristic easier to be solved, and based on the measurement of average internal travel distance. In the Bartholdi \& Gue (2004) formulation, one starts assigning strip doors to the "best doors", i.e. the doors having the smallest average distance to all other doors. Then, one assigns the destinations which receive the most freight to the next-best doors, and so successively.

The approach to treat our specific problem is similar to Bartholdi \& Gue (2004) heuristic. We start the solution process by assuming a standard rectangular layout as in Figure 1, and assign an even number to the total number of dock doors $m_{1}+m_{2}$, thus allowing an equal number of dock doors at each side of the facility (Fig. 1). Next, one assigns strip doors to the "best doors", i.e. the doors having the smallest average distance to all other doors, as in Bartholdi \& Gue (2004).

Considering the random nature of trailer arrivals, the randomness of the unloading times, and the varying occurrence of trailers waiting in the queue, as well as other probabilistic factors, there is no information beforehand on which strip door an arriving trailer will be assigned. Since all strip doors are already assigned at the beginning of the computation model, one can substitute equation (4) by taking the average distance $\bar{d}^{(j)}$ from all the strip doors $i=1,2, \ldots m_{1}$ to stack door $j$

$$
\bar{d}^{(j)}=\left(\frac{\sum_{i=1}^{m_{1}} d_{i, j}}{m_{1}}\right), \quad j=1,2, \ldots, m_{2} .
$$

Now, we sort destinations $j\left(j=1,2, \ldots, m_{2}\right)$ according to the decreasing order of the freight flow $\emptyset_{j}\left(j=1,2, \ldots, m_{2}\right)$. We also sort stack doors according to the increasing order of the average distance $\bar{d}^{(j)}\left(j=1,2, \ldots, m_{2}\right)$, given by (5). The destination with the largest value of $\emptyset_{j}$ is assigned to the stack door with the minimum value of $\bar{d}^{(j)}$. Next, the second largest value of $\emptyset_{j}$ in the list is assigned to the second value of $\bar{d}^{(j)}$ in the corresponding list, and so successively. With this procedure we assign all the $m_{2}$ destinations $j$ to the corresponding best stack doors, thus minimizing (5). This process leads to the minimum value of $\bar{d}$, as required in (4). This procedure has shown to be a simple, but a robust approximate heuristic for the assignment of dock doors.

A door assignment example with $m_{1}=15$ strip doors is shown in Figure 5. First, one assigns strip doors to the "best doors", i.e. the doors having the smallest average distance to all other doors, as in Bartholdi \& Gue (2004). The number of stack doors in the example is $m_{2}=23$, but the volumes of freight to destinations 1 and 2 are significantly higher, requiring one additional door each. Each additional door will be located next to the basic one, forming pairs of twin stack doors. Thus, there will be $m=m_{1}+m_{2}+2=15+23+2=40$ doors. Internal rectangular distances are measured on a system of coordinates with its origin at the southwestern edge of the facility (Fig. 5). Furthermore, the 40 doors are numbered in two layers along the south and the 
north edge of the terminal, as shown in Figure 5. As long as the doors positions are defined, a matrix with the distances between doors is easily computed.

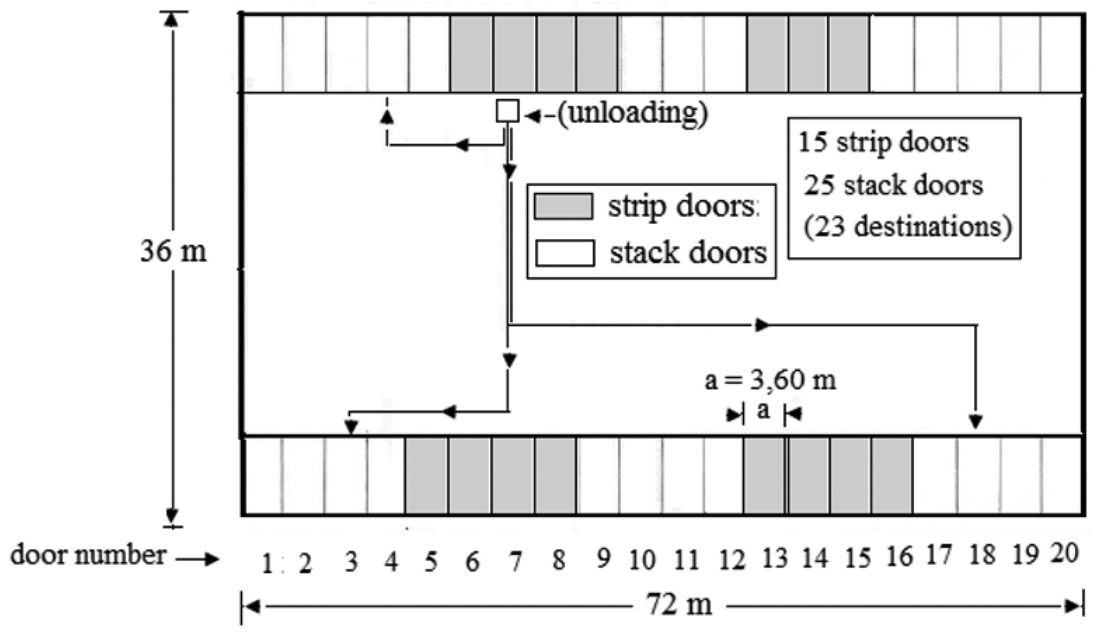

Figure 5 - Door assignment example.

Compute now the average distances $\bar{d}^{(j)},\left(j=1,2, \ldots, m_{2}\right)$ according to (5), and sort the stack doors according to the increasing order of magnitude of $\bar{d}^{(j)}$, as shown in Table 1. Then, assign the door with the least value of $\bar{d}^{(j)}$, (door \#9, with $\bar{d}^{(9)}=29.52 \mathrm{~m}$ ), to the destination $j$ with the greatest value of $\emptyset_{j}$, i.e. $\emptyset_{1}=7,740$, and so successively, as shown in Table 1 , columns (d) and (h) respectively. Notice that door 10 , adjacent to door 9 , was also assigned to destination 1 , as explained, forming a pair of contiguous doors. The same occurs with stack doors 11 and 12 , assigned jointly to destination \#2. Table 1 shows the assignment of doors for this example, a routine repeated for the other alternative layouts with varying values of $m_{1}$.

\subsection{Trailer unload scheduling}

Although Newell (1971) mentions some simple examples of queueing problems with disciplines different from the FCFS configuration, it is implicit in his method the adoption of the latter discipline. Besides, the adoption of a different queueing discipline in this work, to be described next, involves more complex mathematical formulation as compared to the FCFS alternative. Thus, a supplementary simulation model was developed in order to bypass such difficulty. For this, the Arena simulation software, Version 14.0, was used. In the simulation model, when an inbound trailer $k\left(1,2, \ldots, n_{V}\right)$ arrives at the terminal it is assigned to a module identified as Reception. Then, a virtual badge is assigned to the trailer $k$, and it remains stuck on it until the vehicle is finally assigned to a strip door in order to be unloaded. Let us assume that the vehicle $k$ has been ultimately assigned to strip door $i$. This vehicle brings a mix of freight represented by vector $V_{k, j}$ (Section 3.1). Each destination $j$ is associated to a specific stack door, as seen in 
Table 1 - Example of stack door assignment (Fig. 5).

\begin{tabular}{|c|c|c|c|c|c|c|c|}
\hline (a) & $\begin{array}{c}(\mathrm{b}) \\
\text { Cartons/ } \\
\text { day }\end{array}$ & $\begin{array}{c}(\mathrm{c}) \\
\text { Stack } \\
\text { door }\end{array}$ & $\begin{array}{c}(\mathrm{d}) \\
\text { Average } \\
\text { dist. (m) }\end{array}$ & $\begin{array}{c}(\mathrm{e}) \\
\text { Destination }\end{array}$ & $\begin{array}{c}(\mathrm{f}) \\
\text { Cartons/ } \\
\text { day }\end{array}$ & $\begin{array}{c}(\mathrm{g}) \\
\text { Stack } \\
\text { door }\end{array}$ & $\begin{array}{c}(\mathrm{h}) \\
\text { Average } \\
\text { dist. (m) }\end{array}$ \\
\hline 1 & 7,740 & 9,10 & 29.52 & 13 & 3,340 & 18 & 44.16 \\
2 & 5,040 & 11,12 & 30.00 & 14 & 3,340 & 23 & 45.84 \\
3 & 3,900 & 30 & 32.16 & 15 & 3,340 & 38 & 46.56 \\
4 & 3,620 & 31 & 32.40 & 16 & 3,340 & 2 & 47.04 \\
5 & 3,460 & 32 & 32.64 & 17 & 3,340 & 19 & 47.76 \\
6 & 3,400 & 25 & 38.64 & 18 & 3,340 & 22 & 49.44 \\
7 & 3,380 & 36 & 39.36 & 19 & 3,340 & 39 & 50.16 \\
8 & 3,360 & 4 & 39.84 & 20 & 3,340 & 1 & 50.64 \\
9 & 3,340 & 17 & 40.56 & 21 & 3,340 & 20 & 51.36 \\
10 & 3,340 & 24 & 42.24 & 22 & 3,340 & 21 & 53.04 \\
11 & 3,340 & 37 & 42.96 & 23 & 3,340 & 40 & 53.76 \\
12 & 3,340 & 3 & 43.44 & & & & \\
\hline
\end{tabular}

Section 3.2. Thus, the average weighted distance to transport freight $V_{k, j}$ from strip door $i$ to all stack doors $j\left(j=1,2, \ldots, m_{2}\right)$ is

$$
\pi_{k, i}=\frac{\sum_{j=1}^{m_{2}} V_{k, j} \times d_{i, j}}{\sum_{j=1}^{m_{2}} V_{k, j}}=\left(\frac{1}{C_{T}}\right) \sum_{j=1}^{m_{2}} V_{k, j} \times d_{i, j},
$$

noticing that the simplification in the second hand side of (6) is due to (2). Therefore, the virtual badge assigned to the incoming vehicle $k$ contains a vector $\pi_{k, i}$ that indicates the average weighted distance from every strip door $i$ to all stack doors contemplated in vector $V_{k, j}$. Thus, the new queue discipline is to put the arriving trailer into the waiting line, and when a generic strip door $i$ becomes available, select the vehicle $k$ in the queue (including an eventual arriving vehicle) that shows the least average distance $\pi_{k, i}$ in its virtual badge. Accordingly, the vehicle $k$ will be assigned to the vacant strip door $i$. In Arena's terms, any incoming trailer is assigned to a sub-model identified as Queue, where it is assigned with the virtual badge $\pi_{k, i}$, and waits its turn to be served. On the other hand, if more than one strip door is vacant, the first selected vehicle from the queue and the corresponding strip door will be such that the value of $\pi_{k, i}$ is minimum among all the candidates among $k$ and $i$. In another words, the arrival order of the trailer will not influence the servicing order, the selecting criteria being only the expected average distance given by (6). This queueing discipline is named LDFS - Least-Distance, First-Served. Gue (1999) argues that this discipline could cause high waiting cost, with trailers stuck in the queue for a long period of time. The effect of this consideration will depend on the freight flow pattern, and on the size of the terminal, the latter reflected by the number of dock doors. Of course, such possible effect can be evaluated through the analysis of the overall cost to be developed in Section 4.3, together with a comparison with the traditional FCFS discipline. A mixed queue discipline, imposing an upper waiting time limit, could also be developed. In the Arena 
software, special queue discipline algorithms can be introduced into the simulation model as Visual Basic sub-programs. Such VB addition, adopting the LDFS discipline, has been performed in this work, in the trailer strip door scheduling module.

\subsection{Inbound trailer arrival process}

Let $t_{0}<\tau_{1}<\tau_{2} \cdots<t_{E}$ be the arrival times of the incoming trailers, where $\lambda(\tau)$ is a continuous function representing the trailer arrival rate. Assume the vehicles are numbered according to the order of their arrival. Figure 6 depicts a typical diagram representing the truck arrival process at a cross-docking terminal, with arrival times restricted to the time window $\left\{t_{0}, t_{E}\right\}$. Such a diagram is based on Odoni \& de Neufville (1992), who dealt with passenger arrivals at airport check-ins. Although it refers to the arrival of passengers at an airport counter, this scheme represents quite well the human behaviour in other operational cases, when clear servicing limitations, in the form of time windows, are observed. First, there is a minimum arrival time restriction in both cases. In the airport situation, the check-in process starts at an established time period before airplane take-off, and analogously, the truck unloading process starts at a pre-defined time $t_{0}$ (Fig. 6). On the other hand, passenger check-in terminates at a given instant governed by the airplane departure time. A similar situation occurs at a cross-docking terminal, with a definite deadline time $t_{E}$ for incoming trailers. Otherwise, if an arrival deadline were not imposed, it might not have enough time to unload the incoming trailers, process the cargo, and load the shipping vehicles in due time.

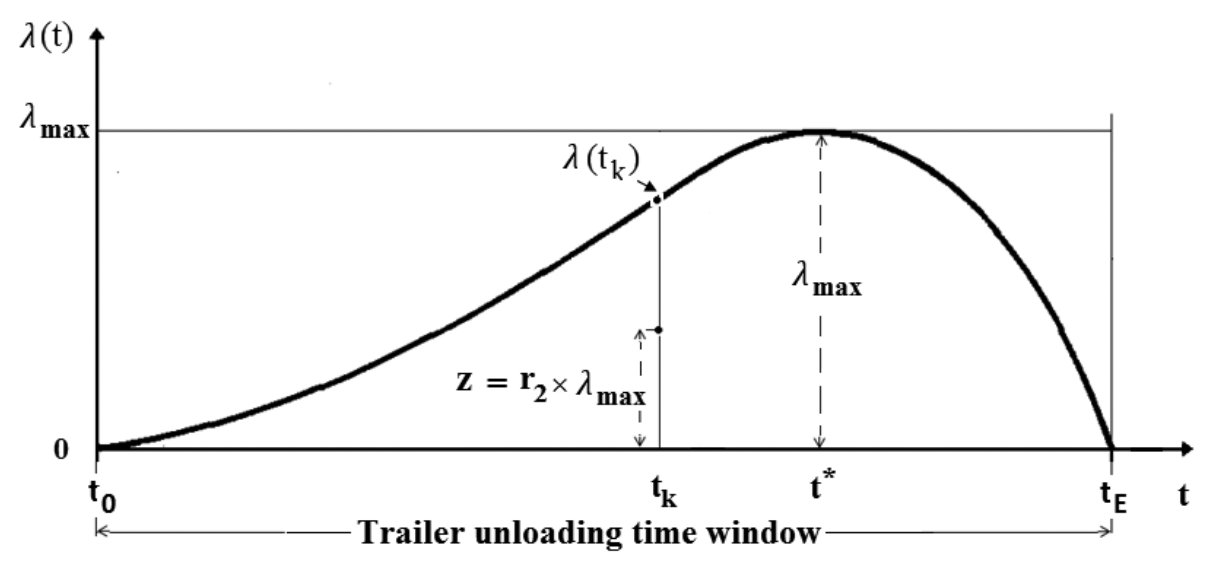

Figure 6 - Inbound trailer arrival pattern.

According to Odoni \& de Neufville (1992), the users (truck operators in this case) adopt, in general terms, the following behaviour pattern. Each incoming vehicle driver tries to choose an arrival time $t$ such that, according to his/her perceptions, it guarantees a 95\% probability (or greater) of respecting the terminal deadline. Thus, one is not considering the absolute value of $t$, but, instead, its perceived or anticipated value, which is strongly influenced by the driver's worse previous experiences, including road traffic conditions, adverse weather situations, etc., as well 
as the punitive measures imposed by the terminal administration to faults, whenever users do not observe the deadline restriction.

When the strip doors are initially opened to unload incoming trailers, the arrival rate is low, and $\lambda(t)$ increases until time $t^{*}$, which is the point of maximum value of $\lambda(t)$ (Fig. 6). It is seen in Figure 6 that $t^{*}$ is not located at the middle point of the time window $\left\{t_{0}, t_{E}\right\}$. In fact, the curve of $\lambda(t)$ is skewed to the right. This situation can be explained by looking at the driver's behaviour, by which, when $t>t^{*}$, his/her preoccupation in not missing the unloading operation increases substantially. Of course, the $\lambda(t)$ pattern depends on the application, but the curve depicted in Figure 6 represents reasonably well the truck driver's behaviour when approaching the cross docking terminal.

A third degree polynomial function was fitted to the curve depicted in Figure 6

$$
\lambda(t)=\omega\left(a t+b t^{2}+c t^{3}\right),
$$

where $\omega \neq 0$, and $a, b$ and $c$ are constants. A third degree equation can be expressed as a function of its roots

$$
\omega\left(t-\tau_{A}\right)\left(t-\tau_{B}\right)\left(t-\tau_{C}\right)=0,
$$

where $\tau_{A}, \tau_{B}$ and $\tau_{C}$ are the roots. Letting $t_{0}=0$ and, in accordance to Figure $6, \lambda\left(t_{0}\right)=0$, one makes $\tau_{A}=0$ in (8). Another root of (8) is $\tau_{B}=t_{E}-t_{0}=L$, since $\lambda(L)=0$ too. It can be shown that equation (8) has a double root at point $t=t_{E}-t_{0}=L$, yielding $\tau_{C}=L$ too. Substituting $\tau_{C}=L$ in (8) one has

$$
\omega t(t-L)^{2}=0
$$

Expanding (9), it results

$$
\lambda(t)=\omega\left[t^{3}-2 L t^{2}+L^{2} t\right] .
$$

In order to determine the value of $\omega$ one imposes that the integral of $\lambda(t)$ in the interval $\left\{t_{0}, t_{E}\right\}$, must be equal to $G$, which is the total quantity of freight received at the terminal during the period $\left\{t_{0}, t_{E}\right\}$, in a typical working day

$$
\int_{t_{0}}^{t_{E}} \omega\left[t^{3}-2 L t^{2}+L^{2} t\right] d t=G
$$

leading to

$$
\omega=\frac{12 G}{L^{4}}
$$

Substituting (12) in (10), one has

$$
\lambda(t)=\left(\frac{12 G}{L^{4}}\right)\left[t^{3}-2 L t^{2}+L^{2} t\right],(0 \leq t \leq L) .
$$

One observes in Figure 6 that the curve $\lambda(t)$ shows a point of maximum in the interval $\left\{t_{0}, t_{E}\right\}$ approximately at $t^{*} \cong\left(\frac{2}{3}\right) L$. In order that $t^{*}$ be a maximum, the first order derivative of $\lambda(t)$ must be zero at that point

$$
\frac{\partial \lambda(t)}{\partial t}=\left(\frac{12 G}{L^{4}}\right)\left[3 t^{2}-4 L t+L^{2}\right]=0
$$


However, $t^{*}=\left(\frac{2}{3}\right) L$ does not satisfy (14), meaning that such point is not a maximum of (13). However, considering the point $t^{* *}=\left(\frac{1}{3}\right) L$, which is symmetric to the point $t^{*}=\left(\frac{2}{3}\right) L$ when one takes the middle point of the $\left\{t_{0}, t_{E}\right\}$ segment as reference, satisfies (14). But, in order that $t^{* *}$ be a point of maximum of (13), the second order derivative of $\lambda(t)$ must be negative at that point

$$
\frac{\partial^{2} \lambda(t)}{\partial t^{2}}=\left(\frac{12 G}{L^{4}}\right)[6 t-4 L]<0,
$$

which is indeed satisfied by $t^{* *}=\left(\frac{1}{3}\right) L$. Therefore, we make a scale transformation $(L-t) \leftarrow$ $t$, leading to

$$
\lambda(t)=\left(\frac{12 G}{L^{4}}\right)\left[(L-t)^{3}-2 L(L-t)^{2}+L^{2}(L-t)\right],(0 \leq t \leq L) .
$$

Now, the point of maximum of $\lambda(t)$ in the interval $0 \leq t \leq L$ is located at $t=\left(\frac{2}{3}\right) L$, as expected. An important function in our analysis is the integral of (13), which will be used further in this paper to compute the average queue length

$$
A(t)=\int_{0}^{t} \lambda(t) d t=G-\frac{12 G}{L^{4}}\left[\frac{(L-t)^{4}}{4}-\frac{2 L(L-t)^{3}}{3}+\frac{L^{2}(L-t)^{2}}{2}\right], 0 \leq t \leq L .
$$

Furthermore, the cumulative probability distribution of $\lambda$ is

$$
F(\lambda)=\frac{A(t)}{G}=1-\left(\frac{12}{L^{4}}\right)\left[\frac{(L-t)^{4}}{4}-\frac{2 L(L-t)^{3}}{3}+\frac{L^{2}(L-t)^{2}}{2}\right]
$$

As mentioned in Section 3.3, the Arena software allows for the introduction of input programs written in Visual Basic, whenever they are not available in the original package. This was necessary with regard to the trailer arrival process represented by the $\lambda(t)$, equation (16). Accordingly, a Visual Basic "Routine.Lambda" sub program was developed and introduced into the Arena software, whose pseudo-code is exhibited in Figure 7.

\subsection{Inbound trailer queueing model}

In the first part of this section the average queue length is determined using Newell's (1971) methodology, which uses continuous approximate queueing models with a FCFS discipline. The application of Newell's (1971) queueing approach to the FCFS configuration presupposes that the underlying system is subject to heavy congestion conditions, meaning in practice that the queue is not empty (Newell, 1971). Optimization is not the objective of the model but, instead, it is a hybrid discrete, continuous, approximate, simulation model. In addition, and using Little's Law (Little, 1961; Little \& Graves, 2008), the corresponding average waiting times are also estimated. 


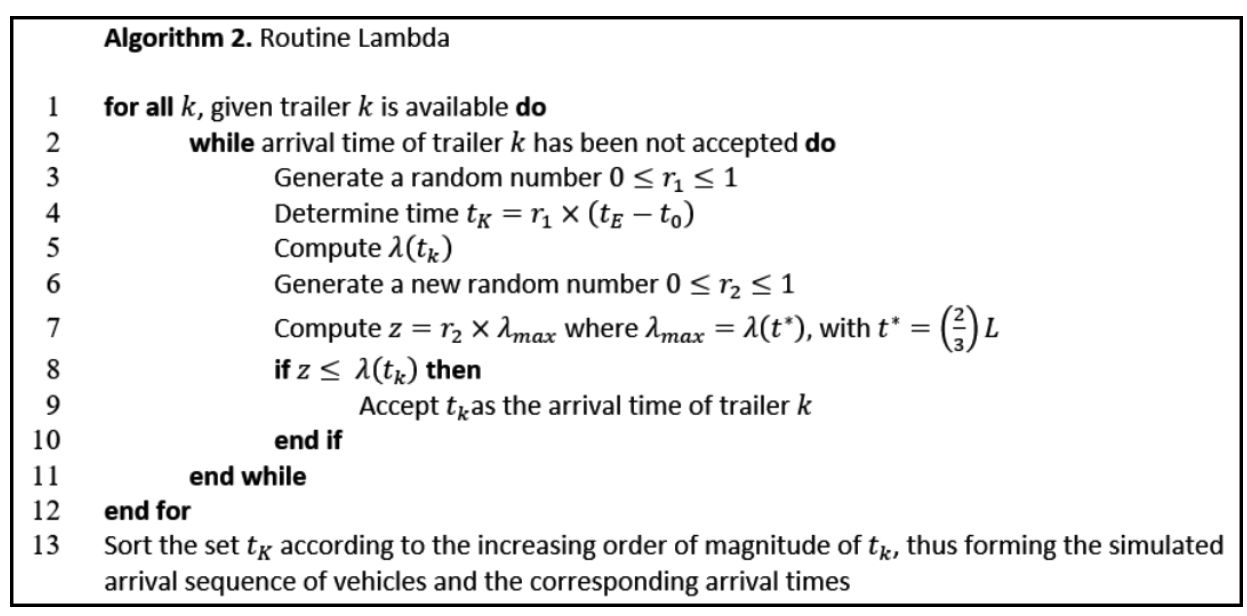

Figure 7 - Pseudo-code to generate a sequence of inbound trailer arrival times.

\subsubsection{Queue length}

Since part of the incoming trailers do not find a vacant strip door upon their arrival at the facility, they may have to wait in order to be served. As mentioned in Section 2.1, classical queueing models generally do not apply to the analysis of queues formed by incoming trucks to be unloaded at cross-docking facilities. In fact, in most cross-docking terminals the queueing process does not reach a stationary state and, furthermore, the trailer arrival rate may vary substantially over the time window period. Thus, a different queue modelling method had to be used instead.

In our research, the formulation developed Newell (1971) has been employed. Newell's approach is intended to analyse non-stationary queues with approximate, straight-forward techniques. Whereas most of the literature on queues deals with equilibrium distributions of queue length and waiting time, the main emphasis of the Newell (1971) approach is on time-dependent behaviour as in this paper, where the arrival rate of users changes along time. The techniques employed by Newell (1971) are mainly fluid and diffusion approximations. Much of the classical theory of queues deals with discrete models, but in simple approximations such as the one adopted here, it is convenient to disregard the discrete nature of some elements and treat them as continuous, or quasi-continuous variables. The fluid approximation adopted in this queuing analysis assumes that the discrete, random arrivals of incoming trailers can be approximated by a deterministic quasi continuum, as it were a fluid flowing into a reservoir (Newell, 1971), and expressed here in cartons. The conversion between trailers to cartons, and vice-versa, is simply done in this application by considering that an incoming trailer always travels fully loaded with $C_{T}$ cartons.

Figure 8 shows a typical cumulative arrival rate $A(t)$, as represented in (17). Assuming a constant service rate $\mu$ per strip door, and $m_{1}$ strip doors in operation, the overall service rate is $\mu m_{1}$. 
Since the service rate is assumed constant, the cumulative service rate $D(t)$ is a straight line function shown in (Fig. 8).

$$
D(t)=a+\mu m_{1} t,
$$

where $a$ is a constant, whose value will be analysed further in this section. Assuming no queue exists at time $t_{0}$, i.e. $Q(0)=0$, the arrival rate $\lambda(t)$ is less than $\mu m_{1}$ in the interval $t_{0} \leq t \leq t_{1}$, when the queue remains essentially nil (Fig. 8). At time $t_{1}$ the slope of $A(t)$ matches $\mu m_{1}$, i.e. $\lambda\left(t_{1}\right)=\mu m_{1}$, and the straight line $D(t)$ is tangent to $A(t)$ at that point (Newell, 1971). Beyond $t_{1}$, one has $\lambda(t)>\mu m_{1}$, and a queue starts to form, with the service rate varying linearly according to (19). The queue length, represented by $Q(t)$, is given by the difference (Newell, 1971)

$$
Q(t)=A(t)-D(t), \quad \text { if } A(t)-D(t) \geq 0 .
$$

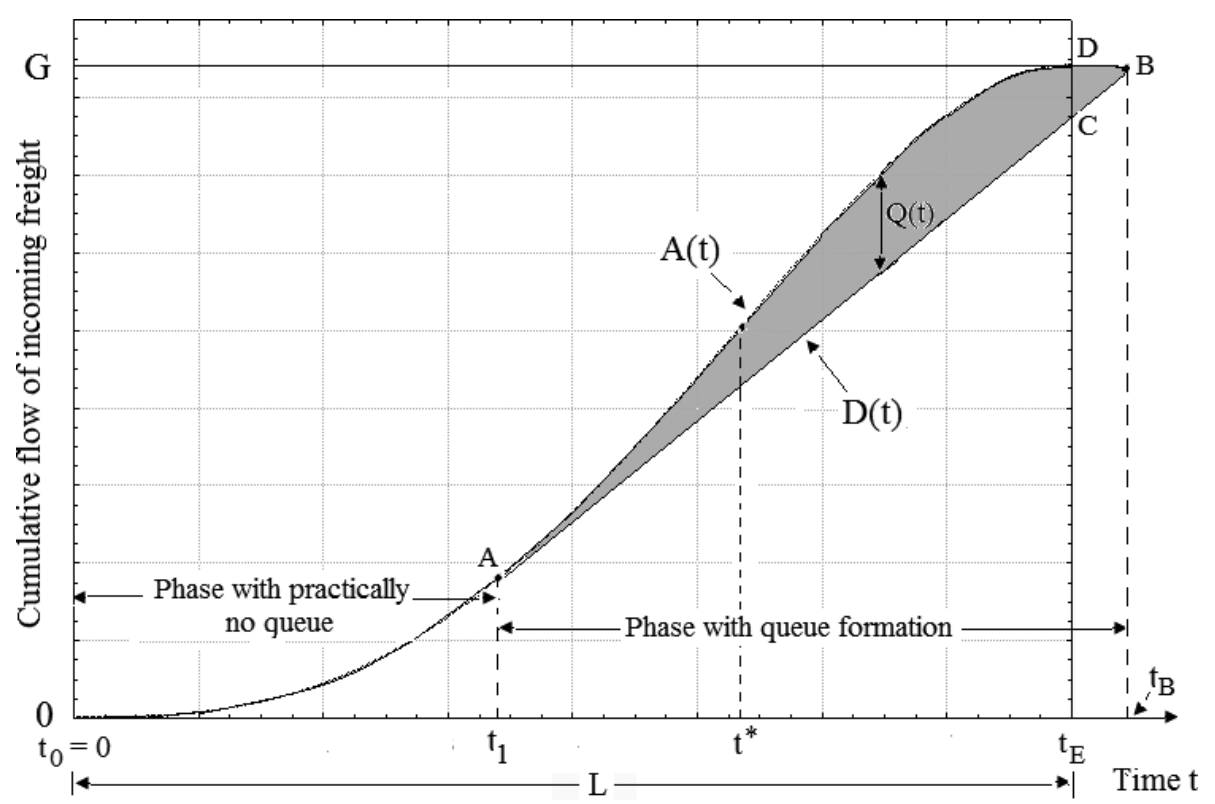

Figure 8-Queue formation when $t_{B}>t_{E}$.

The process ends when $D(t)=G$ (Fig. 8), where $G$ is the total flow of freight received at the terminal during the time interval $\left\{t_{0}, t_{E}\right\}$. The value of $a$ in (19) is determined by means of a local search algorithm. Time $t^{*}$ is the point of maximum $\lambda(t)$ value in the interval $t_{0} \leq t \leq t_{E}$ (Figs. 6 and 8), and thus $t^{*}$ is the inflexion point of curve $A(t)$. Therefore, the search for $a$ is limited to the interval $0 \leq t_{1} \leq t^{*}$, since otherwise the straight line $D(t)$ would not cross the curve $A(t)$, and consequently no queue would be formed. To numerically determine the value of $t_{1}$, one solves the following search problem

$$
\varphi(t)=\min _{t} A b s\left[\lambda(t)-\mu m_{1}\right] \rightarrow t_{1}, \text { in the interval } 0 \leq t \leq t^{*},
$$


where $\lambda(t)$ is given by (16). The function $A b s\left[\lambda(t)-\mu m_{1}\right]$ is unimodal in the interval $0 \leq$ $t_{1} \leq t^{*}$, and problem (21) is solved by means of a golden section search technique (Gerald \& Wheatley, 2004). Constant $a$ is determined by putting $t=t_{1}$ in (19)

$$
a=D\left(t_{1}\right)-\mu m_{1} t_{1},
$$

but, since $D\left(t_{1}\right)=A\left(t_{1}\right)$,

$$
a=A\left(t_{1}\right)-\mu m_{1} t_{1}
$$

Substituting (23) into (19), one has

$$
D(t)=A\left(t_{1}\right)+\mu m_{1}\left(t-t_{1}\right)
$$

An important element in this queue analysis is the point $t_{B}$ where $D\left(t_{B}\right)=G$, i.e. when the last trailer in the queue starts its unloading process, as shown in Figure 8. Varying the number $m_{1}$ of strip doors, the $D(t)$ pattern changes accordingly. In Figure $8, t_{B}>t_{E}$, but other situations may occur, as will be discussed further in this section. Putting $t=t_{B}$ and $D\left(t_{B}\right)=G$ in (24), and solving for $t_{B}$, one has

$$
t_{B}=\frac{G-A\left(t_{1}\right)+\mu m_{1} t_{1}}{\mu m_{1}}, \quad \text { for } t_{B} \geq t_{E}
$$

Three queue cases are analysed next.

\section{Case I: $t_{B} \geq t_{E}$}

As shown in Figure 8, depending on the value of $m_{1}$, and for given values of the other parameters of the problem, a queue may still occur for $t>t_{E}$. No more trailers are accepted to be unloaded when $t>t_{E}$, but a group of remaining trailers are still in the queue, and must be served until the waiting line reaches zero. In this case, the queue is analysed in the time interval $t_{0} \leq t \leq t_{B}$, separated in three parts (Fig. 8)

a) $Q(t)=0$, for $0<t<t_{1}$;

b) $Q(t)=A(t)-D(t)$, for $t_{1} \leq t \leq t_{E}$;

c) $Q(t)=G-D(t)$, for $t_{E}<t \leq t_{B}$.

The average queue length, expressed now in number of vehicles, is (Fig. 8)

$$
\bar{Q}=\frac{\left\{\int_{t_{1}}^{t_{E}}[A(t)-D(t)] d t+\int_{t_{E}}^{t_{B}}[G-D(t)] d t\right\}}{t_{B} * C_{T}} .
$$

\section{Case II: $t_{B}<t_{E}$ and $t_{1}<t^{*}$}

If $t_{1}<t^{*}$, the tangent $D(t)$ to the curve $A(t)$, at time $t_{1}$ (point $A$, Fig. 9), crosses curve $A(t)$ at point $C$, with abscissa $t_{Z}$. Thus, the phase with queue formation comprises the time interval $\left\{t_{1}, t_{Z}\right\}$, as shown in Figure 9. Accordingly, the queue is thus defined 
d) $Q(t)=0$, for $0 \leq t<t_{1}$ and for $t>t_{Z}$,

e) $Q(t)=A(t)-D(t)$, for $t_{1} \leq t \leq t_{Z}$.

To determine $t_{Z}$, a golden section search technique was employed in the interval $t^{*} \leq t \leq t_{E}$ (Gerald \& Wheatley, 2004), as follows

$$
\vartheta(t)=\min _{t} A b s[A(t)-D(t)] \rightarrow t_{Z}, t^{*} \leq t \leq t_{E},
$$

f) The average queue length is (Fig. 9)

$$
\bar{Q}=\left\{\int_{t_{1}}^{t_{Z}}[A(t)-D(t)] d t\right\} /\left(t_{E} \times C_{T}\right)
$$

\section{Case III: $t_{B}<t_{E}$ and $t_{1}<t^{*}$}

As long as the number of strip doors $m_{1}$ increases, it is observed that

$$
\lim _{m_{1} \rightarrow \infty} t_{1} \rightarrow t^{*}
$$

And, since $t_{1}$ converges to the inflexion point $t^{*}$, the tangent $D(t)$ to curve $A(t)$ tends to be above $D(t)$ in the interval $t^{*} \leq t \leq t_{E}$, and therefore, in the limit, $D(t)$ will not cross $A(t)$. Consequently, in this specific case, $Q(t) \rightarrow 0$ as $t_{1} \rightarrow t^{*}$. Nevertheless, Newell (1971) points out that the fluid analogy requires that the queue will remain large enough so that the cumulative number of departures might approximately be represented by a non-random (quasi) continuous variable. Otherwise, when Case III occurs with $\lambda(t)<\mu m_{1}$, the fluid analogy should not be applied (Newell, 1971). In practical terms, when searching for a number of strip doors with minimum total cost, the optimal solution will normally be under Case I or II.

\subsubsection{Trailer waiting time}

Little's Law (Little, 1961; Little \& Graves, 2008) states that, under steady state condition, the average number $\bar{Q}$ of items in a queue line equals the average arrival rate $\bar{\lambda}$, multiplied by the average time $\bar{W}_{t}$ that an item spends in the queue or in the system, depending on the application and on the analytic framework (Little \& Graves, 2008). The law is

$$
\bar{Q}=\bar{\lambda} * \bar{W}_{t}
$$

This relationship is remarkably simple and general. Theoretically, Little's Law requires stationarity conditions about the underlying stochastic processes, but it is quite surprising that it can be employed more generally (Little \& Graves, 2008). Little's Law provides a fundamental relationship among three key parameters in a queuing system. In fact, the system can be very general. An important feature of Little's Law is that, by knowing two of the three parameters, the third 


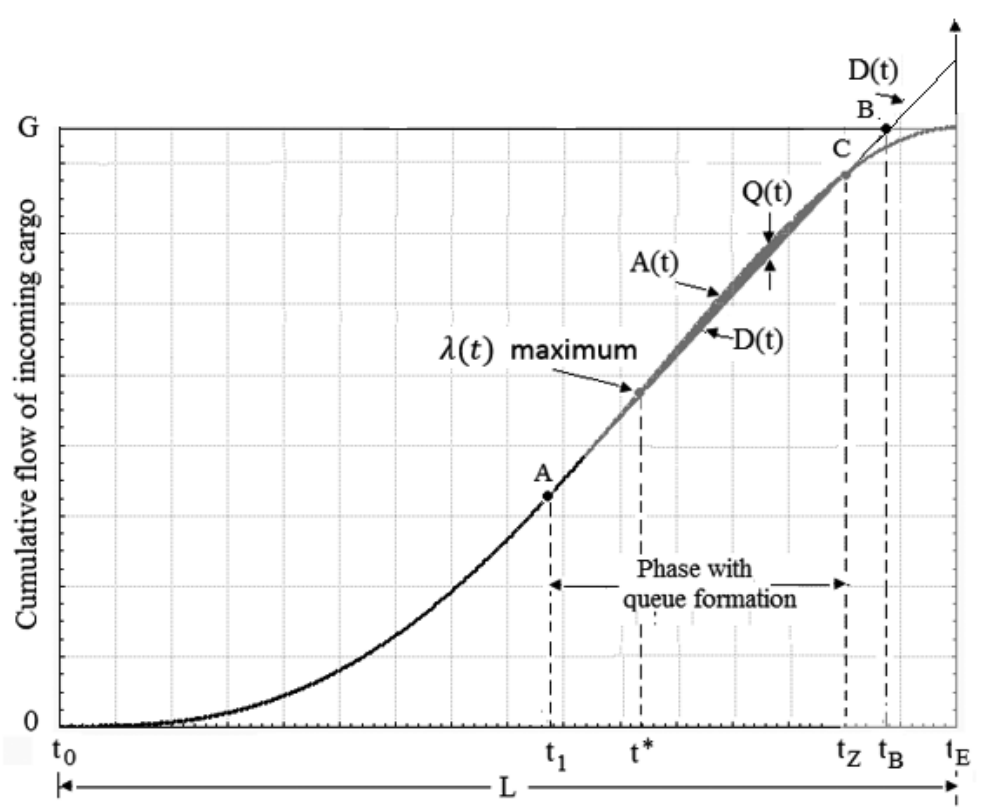

Figure 9 - Case II: Queue occurring when $t_{1}<t<t_{Z}$.

one can be calculated directly. This is a useful property since measurements of all three parameters may be difficult in certain applications. Little's Law presents great robustness and generality. It is exact even in cases when arrival service processes are not stationary. The essential condition is to have a finite time window of observations that starts and stops when the system is empty (Little \& Graves, 2008).

This is the case of the queuing process studied in this paper. For this, let us consider Case I first (Section 3.5.1). The total number of units that arrive during the interval $t_{0} \leq t \leq t_{B}$ is $G$ (Fig. 9), letting $\bar{\lambda}=G /\left(t_{B}-t_{0}\right)$. On the other hand, the average number of freight units $\bar{Q}$ in the queue is given by expression (29). Conversely, for Case II one has $\bar{\lambda}=G /\left(t_{E}-t_{0}\right)$, with $\bar{Q}$ given by expression (33).

\section{EXPERIMENTAL RESULTS AND ANALYSIS}

\subsection{Model flow chart}

The flow chart of the underlying model is presented in Figure 10. After the introduction of the input data (Section 4.2), the model starts defining the elements concerning the inbound trailer arrival process, analysed in Section 3.4 (block 1, Fig. 10). The trailer servicing process follows a log-normal distribution of the unloading time, with parameters defined in Table 2. Next, the inbound freight flows are generated through a Monte Carlo process, as described in Section 3.1 (block 2, Fig. 10). 


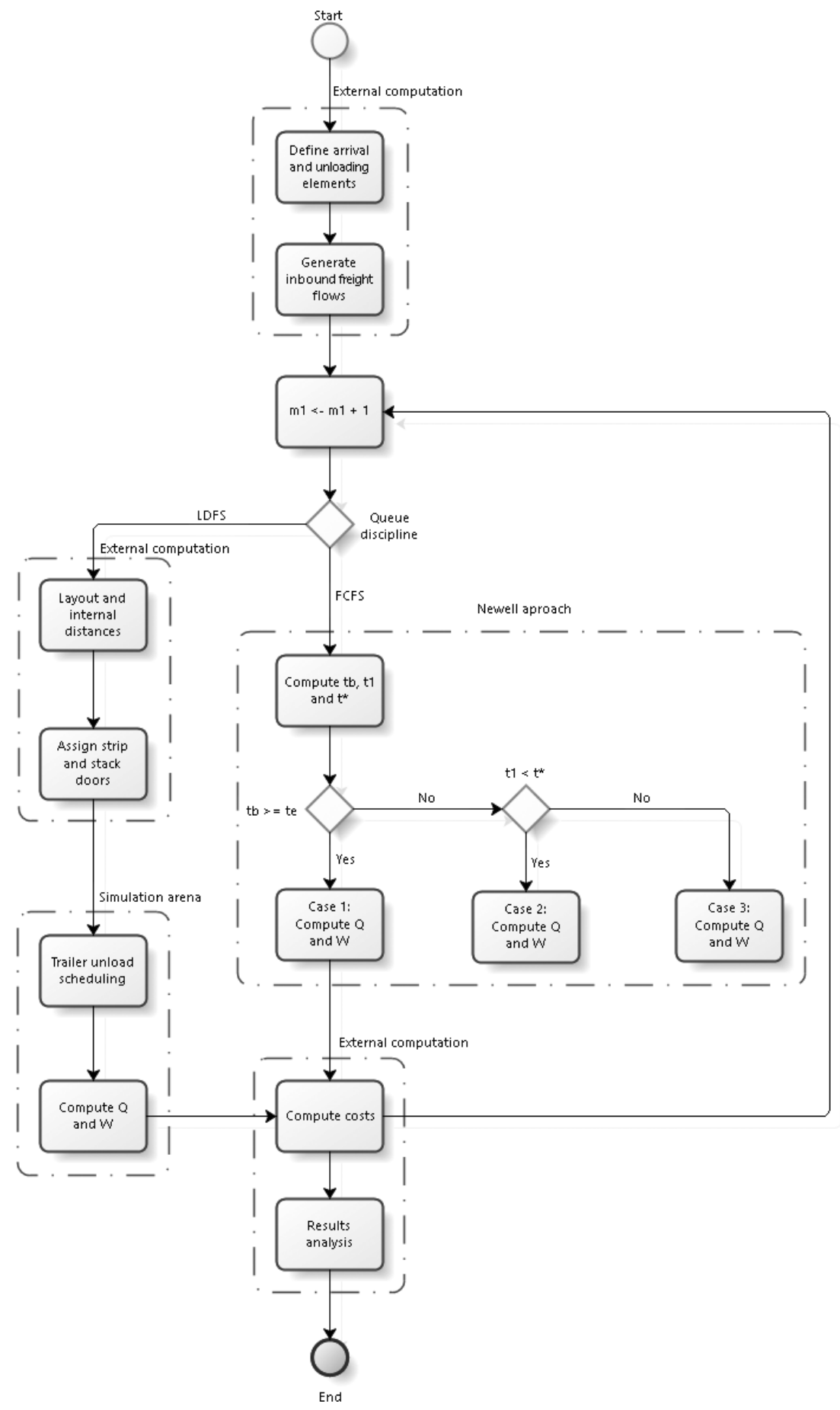

Figure 10 - Model flow chart. 
The basic decision variable of the model is the number $m_{1}$ of strip doors (block 3 ). The variation of $m_{1}$ was set by empirically evaluating the congestion level of the dock, leading to a minimum of 9 , and a maximum of 19 strip doors. Next, in block 4, the queue discipline is contemplated. For the FCFS discipline, the Newell approach was employed (blocks 5 to 10). The average queue length $\bar{Q}$ is estimated according to three alternative formulations, represented by Cases I, II, and III, and analysed in Section 3.5.1. On the other hand, the average waiting time $\bar{W}$ was estimated using Little's law, Section 3.5.3.

Costs are computed in block 15 (Fig. 10) following the methodology to be described in Section 4.3. Finally, the results of the work (block 16) are analysed in Section 4.4. Table 2 shows the main input data used in the analysis.

Table 2 - Main input data to the model.

\begin{tabular}{|c|c|c|c|}
\hline Input symbol & Description & Value & Unit \\
\hline $\mathrm{G}$ & Total freight flow per day & 84,000 & Cartons \\
\hline$n_{V}$ & Number inbound vehicles & 60 & Vehicles/day \\
\hline$m_{1}$ & Number of strip doors (main variable) & $9,11,13,15,17,19$ & Units \\
\hline$m_{2}$ & Number of freight destinations & 23 & Units \\
\hline$m_{2}+2$ & Number of stack doors (see Section 4.2.1) & 25 & Units \\
\hline$C_{T}$ & Trailer capacity & 1,400 & Cartons \\
\hline$L$ & Trailer unloading time window extension & 8 & Hours \\
\hline$\overline{\bar{\lambda}}$ & Average trailer arrival rate & 10,500 & Cartons/hour \\
\hline$\lambda_{\max }$ & Maximum trailer arrival rate & $18,666.67$ & Cartons/hour \\
\hline $\bar{s}$ & Average trailer unloading rate ${ }^{(*)}$ & 933.33 & Cartons/hour \\
\hline$\sigma_{S}$ & Standard deviation trailer unloading rate ${ }^{(*)}$ & 280.00 & Cartons/hour \\
\hline
\end{tabular}

(*) Lognormal distribution.

\subsection{Incoming trailer queue simulation with $L D F S$ discipline}

The structure of the queuing model with LDFS discipline was described in section 3.3. The simulation was developed in Arena, version 14.0. In order to define the LDFS structure in detail, it was necessary to first schematize the layout of the terminal, setting its dimensions and door positions, and defining the distance matrices between doors for all the strip door alternatives (block 11, Fig. 10). Next, the strip doors are first assigned (block 12, Fig. 10), followed by the stack doors, as discussed in Section 3.2. Computations in blocks 11 and 12 (Fig. 10) were developed in Visual Basic and inserted in the Arena software. Blocks 13 and 14 correspond to Arena proper computations. Block 13 deals with the trailer scheduling process analysed in Section 3.3. Finally, the average queue length $\bar{Q}$ and the average waiting time $\bar{W}$ are computed by the Arena software (block 14, Fig. 10).

Since the number of stack doors is fixed and equal to 25 (Table 2), we adopted a varying odd number of strip doors in such that the total number of operating doors (strip plus stack) would be an even number, thus letting a fully symmetric door configuration on both sides of the terminal. 
Accordingly, the number $m_{1}$ of strip doors covers the range from 9 to 19 , in odd increments, as shown in Table 2.

The central variable of interest here is the mean number of incoming trailers in the queue. The number of replications in the simulation was set with the help of Arena's Output Analyzer, assuming a $\alpha=95 \%$ confidence interval and adopting an intermediate configuration of $m_{1}=15$ strip doors. Tentatively assuming a number $n_{r}^{(1)}=50$ of replications, the Arena Output Analyzer yielded the half-width confidence interval $h=0,255$, and the standard deviation of the sample $s=0.896$. A recursive approximate formula (Kelton et al., 2014; Rubisntein \& Kroese, 2017) was used to further estimate the value of $n_{r}$, based on the first guess

$$
n_{r}^{(2)}=t_{n_{r}-1,1-\frac{\alpha}{2}}^{2}\left(\frac{s^{2}}{h^{2}}\right),
$$

where $t_{n_{r}-1,1-\frac{\alpha}{2}}^{2}$ is the critical value of the $\mathrm{t}$ statistics. Approximating the $t$ variable by the corresponding normal critical value $z_{1-\alpha / 2}$, one has

$$
n_{r}^{(2)} \cong z_{1-\frac{\alpha}{2}}^{2}\left(\frac{s^{2}}{h^{2}}\right) .
$$

For $\alpha=95 \%, z_{1-\alpha / 2}=1.96$, and putting $s=0.896$ and $h=0,255$ in (37), one gets $n_{r}^{(2)}=$ 47. Thus, the round number of replications $n_{r}=50$ attends well the $95 \%$ confidence interval requirement.

The hardware to process the simulation has an Intel i5 3570 processor, with an 8 GB RAM, and SSD 500gb Samsung 850 Evo. The average time to run 50 replications of each configuration, represented by the number $m_{1}$ of strip doors, was 119.3 seconds, ranging from 91 to 135 seconds. Average queue length, queue length standard deviation, and trailer waiting time, both for the FCFS and the FDFS disciplines, and obtained via simulation, are presented in Table 3 and depicted in Figure 11.

\subsection{Cost analysis}

The objective of the comprehensive model is to minimize the sum of three costs: (a) the rent cost of the terminal building facility, which is a function of its area and layout; (b) the waiting cost of inbound trailers when being attended at the terminal, and (c) the cost of handling and moving freight inside the terminal, which depends upon the material handling equipment in use and upon the facility layout. The costs related to outbound trucks are fixed in our problem, since the assignment of those trucks to stack doors is done externally to the model, as indicated in Section 2.2, and therefore they do not influence the search for the minimum cost.

\subsubsection{Economic rent of the facility}

Let $m$ be the total number of dock doors located on both sides of the rectangular facility. Usually, the number of stack doors is greater than the number of destinations $m_{2}$, because some destina- 
Table 3 - Inbound trailer queueing simulation results.

\begin{tabular}{|c|c|c|c|c|c|c|}
\hline & \multicolumn{3}{|c|}{ FCFS discipline } & \multicolumn{3}{c|}{ LDFS discipline } \\
\hline $\begin{array}{c}\text { Number } \\
\text { of strip } \\
\text { doors } \\
\left(m_{1}\right)\end{array}$ & $\begin{array}{c}\text { Average } \\
\text { queue } \\
\text { length } \\
\text { (vehicles) }\end{array}$ & $\begin{array}{c}\text { Queue } \\
\text { standard } \\
\text { deviation }\end{array}$ & $\begin{array}{c}\text { Average } \\
\text { waiting } \\
\text { time } \\
\text { (hour) }\end{array}$ & $\begin{array}{c}\text { Average } \\
\text { queue } \\
\text { length } \\
\text { (vehicles) }\end{array}$ & $\begin{array}{c}\text { Queue } \\
\text { standard } \\
\text { deviation }\end{array}$ & $\begin{array}{c}\text { Average } \\
\text { waiting } \\
\text { time } \\
\text { (hour) }\end{array}$ \\
\hline 9 & 8.30 & 1.16 & 1.83 & 7.76 & 1.31 & 1.97 \\
\hline 11 & 5.70 & 1.35 & 1.13 & 5.11 & 1.20 & 1.21 \\
\hline 13 & 3.98 & 1.13 & 0.72 & 2.91 & 1.61 & 0.76 \\
\hline 15 & 2.34 & 0.92 & 0.40 & 1.22 & 1.02 & 0.51 \\
\hline 17 & 1.20 & 0.56 & 0.19 & 0.64 & 0.65 & 0.34 \\
\hline 19 & 0.67 & 0.44 & 0.11 & 0.29 & 0.24 & 0.21 \\
\hline
\end{tabular}

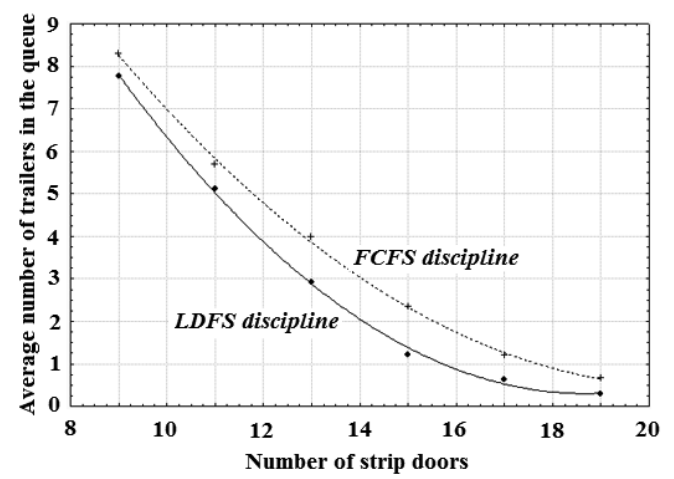

(a) Expected vehicle queue length

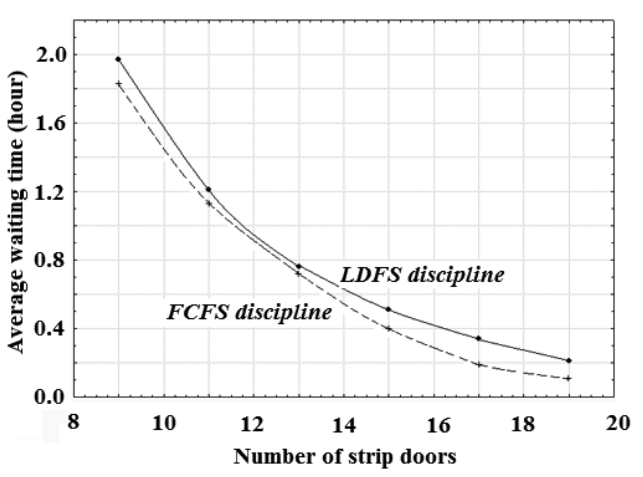

(b) Expected trailer waiting time

Figure 11 - Inbound trailer queue length and waiting time.

tions may show a larger freight flow level, requiring more than one stack door for shipping the cargo (Bartholdi \& Gue, 2004). In this application, destinations 1 and 2 have shown larger volumes (see Fig. 2), thus requiring one additional stack door each, as to handle excess freight to these destinations. So, the total number of dock doors is $m=m_{1}+m_{2}+2$ in this application.

Figure 5 (Section 3.2) shows the internal arrangement of the dock doors as well as the basic terminal dimensions for an example with $m_{1}=15, m_{2}=23$ and $m=25$. The door width is $a=3.60 \mathrm{~m}$, and the internal width of the facility is $b=36 \mathrm{~m}$. Since $m$ was assumed in the model to be an even number, there will be $m / 2$ doors on each side of the building. An additional area of $400 \mathrm{~m}^{2}$ was assigned for administrative activities. Therefore, the facility area will be in general

$$
A=\left(\frac{m_{1}+m_{2}+2}{2}\right) \times a \times b+400(\text { sq.meter }) .
$$

The operating cost of the terminal was based on a similar facility located in Tucson, AZ, USA (Boyd Co., 2013), with an approximate annual cost of US\$266.70/year/sq.meter, which con- 
verted to the BRL Brazilian currency (at an exchange rate of 3.28 BRL\$ to the US dollar) lead to BRL \$ 874.73/year/sq.meter. On the other hand, inbound vehicles require a parking space when waiting to be unloaded, circa 120 sq. meter per trailer. A margin of $20 \%$ has been added to cover circulation, control space, and eventualities, leading to an estimated area of 144 sq. meter of parking space per trailer. In its turn, the land to be reserved as a parking lot for the inbound trailers was assumed to be worth BRL\$ 400.00 per $m^{2}$, to be amortized in 15 years, with a yield annual rate of $8.5 \%$.

Table 4 shows the total annual rent cost of the terminal. Since the total freight flow through the terminal is $G=84,000$ cartons per working day, the last column in Table 4 shows the average terminal rent cost per carton. It was assumed 300 working days per year.

Table 4 - Facility rent cost as a function of the number of strip doors.

\begin{tabular}{|c|c|c|}
\hline $\begin{array}{c}\text { Number of } \\
\text { strip doors } \\
\left(m_{1}\right)\end{array}$ & $\begin{array}{c}\text { Total terminal } \\
\text { rent cost } \\
\text { (BRL\$working day) }\end{array}$ & $\begin{array}{c}\text { Average facility rent } \\
\text { cost per carton } \\
\text { (BRL\$) }\end{array}$ \\
\hline 9 & 7821.06 & 0.093 \\
\hline 11 & $8,153.89$ & 0.097 \\
\hline 13 & $8,506.91$ & 0.101 \\
\hline 15 & $8,862.85$ & 0.105 \\
\hline 17 & $9,241.91$ & 0.110 \\
\hline 19 & $9,594.93$ & 0.114 \\
\hline
\end{tabular}

\subsubsection{Inbound trailer waiting cost}

The estimated trailer waiting times for queue disciplines FCFS and LDFS are exhibited in Table 3 and Figure 11. Analysing empirical data related to Brazilian freight transport, an estimated average rental cost of $C_{t r l}=\mathrm{BRL} \$ 40.00$ per hour, per trailer was defined. Thus, the total average waiting cost of incoming trailers is

$$
\bar{C}_{W t}^{(\delta)}=n_{V} \times C_{t r l} \times \bar{W}^{(\partial)} / G,
$$

where $\bar{C}_{W t}^{(\delta)}$ is the average inbound trailer waiting cost per carton, for queue discipline $\delta, n_{V}$ is the number of inbound trailers per day; $C_{t r l}$ is the average trailer rental cost per hour; $\bar{W}^{(\partial)}$ is the average trailer waiting time for queue discipline $\delta$, and $G=84,000$ cartons is the total daily freight flow through the terminal. Table 5 presents the values of $\bar{C}_{W t}^{(\delta)}$ as a function of the number of strip doors and queue discipline.

\subsubsection{Cost for handling freight inside the terminal}

Since the cross dock terminal studied in this paper is a small one by international standards, and since in developing countries there is quite a number of terminals still manually operated, we 
Table 5 - Inbound trailer waiting cost as a function of the number of strip doors.

\begin{tabular}{|c|c|c|c|c|}
\hline $\begin{array}{c}\text { Number of } \\
\text { strip doors }\end{array}$ & \multicolumn{2}{|c|}{ Queue discipline: FCFS } & \multicolumn{2}{c|}{ Queue discipline: LDFS } \\
\hline$m_{1}$ & $\begin{array}{c}\text { Average inbound } \\
\text { trailer waiting cost } \\
\text { (BRL\$/day) }\end{array}$ & $\begin{array}{c}\text { Average cost } \\
\text { per carton } \\
\text { (BRL\$) }\end{array}$ & $\begin{array}{c}\text { Average inbound } \\
\text { trailer waiting cost } \\
\text { (BRL\$/day) }\end{array}$ & $\begin{array}{c}\text { Average cost } \\
\text { per carton } \\
\text { (BRL\$) }\end{array}$ \\
\hline 9 & $4,392.00$ & 0.052 & $4,728.00$ & 0.056 \\
\hline 11 & $2,712.00$ & 0.032 & $2,904.00$ & 0.035 \\
\hline 13 & $1,728.00$ & 0.021 & $1,824.00$ & 0.022 \\
\hline 15 & 960.00 & 0.011 & $1,224.00$ & 0.015 \\
\hline 17 & 456.00 & 0.005 & 816.00 & 0.010 \\
\hline 19 & 214.00 & 0.003 & 504.00 & 0.006 \\
\hline
\end{tabular}

decided to examine two situations. The first one, using manually operated four-wheel platform dollies, and the second, employing electric pallet trucks.

\section{A - Freight handling with four-wheel platform dollies}

The four-wheel platform truck is $0.81 \mathrm{~m}$ long and $0.73 \mathrm{~m}$ wide, carrying loads up to $1,800 \mathrm{~kg}$ and taking about 20 cartons per voyage. A worker takes circa 6 minutes to arrange 20 cartons on a dolly, with the opposite operation taking approximately the same time. Thus, the effort to load and unload the dollies, for a total flow of 84,000 cartons per day, will require a total of 840 manhours/day. Assuming a speed of 3 meter/sec for a worker moving a dolly across the facility, with an average travelled distance of $d$ meters between the strip and the stack door, the estimated dolly cycle time is $t_{\text {Cycle }}=2 d / 3$ seconds. Since 20 cartons are transported in each cycle, the number of cycles per day will be $84,000 / 20=4,200$ cycles. Thus, the daily labour effort to displace the freight across the facility is 0.778 man-hours/day/meter.

Introducing two correcting factors, the total daily labour effort of handling and moving freight across the terminal, with four-wheel dollies, is

$$
H_{d}=(1+\alpha) \times(840+0.778 d) / \epsilon
$$

where $H_{d}$ is the total labour effort in man-hours per working day, $d$ is the average internal distance between strip and stack doors, in meters as estimated in Section 3.3, $\alpha=0.3$ is a margin to cover unexpected demand variations, and $\epsilon=0.7$ is the estimated labour efficiency.

Personnel assigned to this kind of job receives an estimate of 1.9 minimum legal wages, or BRL\$ $1,680.00$ per month, plus legal obligations of $83.3 \%$, leading to a gross wage of BRL\$ 3,062.80 per month. Considering a total of 25 working days per month, a worker will get BRL\$ 122.50 per working day, or BRL\$ 15.30 per hour of work. A dolly acquisition cost is BRL\$ 600.00, with an estimated life of 3 years. Considering 300 working days per year, one has a dolly cost of BRL $\$ 0.73 /$ day. About 200 dollies were estimated to attend the internal transport 
service, leading to a subtotal cost of BRL\$ 146.00/day. The cost of handling freight per day for this version is depicted in Table 6.

Table 6 - Cost for moving freight inside the terminal with four-wheel platform dollies.

\begin{tabular}{|c|c|c|c|c|}
\hline $\begin{array}{c}\text { Number of } \\
\text { strip doors }\end{array}$ & \multicolumn{2}{|c|}{ Queue discipline: $F C F S$} & \multicolumn{2}{|c|}{ Queue discipline: $L D F S$} \\
\hline$m_{1}$ & $\begin{array}{c}\text { Total internal } \\
\text { transport } \\
\text { cost/day } \\
\text { (BRL\$) }\end{array}$ & $\begin{array}{c}\text { Average cost } \\
\text { per carton } \\
\text { (BRL\$) }\end{array}$ & $\begin{array}{c}\text { Total internal } \\
\text { transport } \\
\text { cost/day } \\
\text { (BRL\$) }\end{array}$ & $\begin{array}{c}\text { Average cost } \\
\text { per carton } \\
\text { (BRL\$) }\end{array}$ \\
\hline 9 & $24,822.43$ & 0.296 & $24,738.64$ & 0.295 \\
\hline 11 & $24,867.08$ & 0.296 & $24,786.84$ & 0.295 \\
\hline 13 & $24,891.84$ & 0.296 & $24,822.21$ & 0.296 \\
\hline 15 & $24,940.48$ & 0.297 & $24,865.31$ & 0.296 \\
\hline 17 & $25,001.05$ & 0.298 & $24,902.45$ & 0.296 \\
\hline 19 & $25,068.25$ & 0.298 & 24.942 .69 & 0.297 \\
\hline
\end{tabular}

\section{B - Freight handling with electric pallet trucks}

The electric pallet truck is a Hyster Spectrum P20S, with a $112.5 \mathrm{~cm}$ long fork and about 2,000 kg load capacity. General operating data are as follows

- Travelling speed: $220 \mathrm{ft} / \mathrm{min}=1.12 \mathrm{~m} / \mathrm{sec}$;

- Pallet length $1.20 \mathrm{~m}$, width $1.00 \mathrm{~m}$;

- Cartons per pallet: 50;

- Time to reach a pallet and lift it: $3 \mathrm{sec}$;

- Time to lower a pallet and liberate it: $3 \mathrm{sec}$;

- Time margin related to delays, traffic idle time, etc.: 30\%;

- Overall operating efficiency: $70 \%$.

Thus, the pallet truck cycle time is

$$
t_{t r k}=(1+\alpha)\left[2 \times 3+\frac{2 d}{1.12}\right] /(60 \times \epsilon),
$$

where $t_{\text {trk }}$ is the pallet truck cycle time in minutes, $\alpha=0.30$ is the time margin, $d$ is the average rectangular distance from the strip door to the stack door in meters, and $\epsilon=0.7$ is the overall operating efficiency. Since a pallet truck operates $T=8$ hours $=480$ minutes per day, the number of cycles it will perform per day is

$$
n_{c y c l}^{\left({ }^{t r k}\right)}=\frac{480}{(1+\alpha)\left[6+\frac{2 d}{1.12}\right] /(60 \times \epsilon)}=\frac{28,800 \varepsilon}{(1+\alpha)\left[6+\frac{2 d}{1.12}\right]}
$$


The total expected number of pallet truck cycles per day $n_{T}$ is equal to the total daily freight flow $G=84,000$ cartons divided by the number of cartons per pallet, or $84,000 \div 50=1,680$ cycles/day. Since the pallet truck operates $T=8$ hours $=480$ minutes per day, the required number of trucks is

$$
n_{t r k}=\frac{1.10 \times 1680}{n_{c y c l}^{(t r k)}},
$$

which includes an excess of $10 \%$ to take care for out-of-order trucks, periodic maintenance, etc. The annual rent of a pallet truck is BRL $\$ 84,820.60$, or BRL $\$ 282.73$ per working day. The basic wage of a pallet truck operator is BRL\$2,361.70 per month. Adding legal obligations of 83.3\%, one has a total wage value of BRL\$ 4,329.00 per worker and per month, or BRL\$ 173.16 per working day.

Since freight does not arrive palletized, the cargo must be palletized just upon the unloading operation at the terminal. It requires 5 man-hours to palletize 1,000 cartons. Since a total of 84,000 cartons are handled per day, an effort of 420 of man-hours/day is necessary to palletize all the freight. For a total operation period of $T=8$ hours per day, it will require $420 / 8 \cong 52,2$ men. Adding a $10 \%$ margin, it leads to a total of 58 workers to perform the palletization task. The labour cost related to this kind of service is the same adopted in Section 4.2.3A, i.e. BRL\$122.70 per day, per man, or BRL\$ 7,116.60 per working day.

Table 7 presents the costs for handling and moving freight inside the terminal for the electric pallet truck configuration.

Table 7 - Cost for moving freight inside the terminal with electric pallet trucks.

\begin{tabular}{|c|c|c|c|c|}
\hline $\begin{array}{c}\text { Number of } \\
\text { strip doors }\end{array}$ & \multicolumn{2}{|c|}{ Queue discipline: FCFS } & \multicolumn{2}{|c|}{ Queue discipline: $L D F S$} \\
\hline$m_{1}$ & $\begin{array}{c}\text { Total internal } \\
\text { transport } \\
\text { cost/day } \\
\text { (BRL\$) }\end{array}$ & $\begin{array}{c}\text { Average cost } \\
\text { per carton } \\
\text { (BRL\$) }\end{array}$ & $\begin{array}{c}\text { Total internal } \\
\text { transport } \\
\text { cost/day } \\
\text { (BRL\$) }\end{array}$ & $\begin{array}{c}\text { Average cost } \\
\text { per carton } \\
\text { (BRL\$) }\end{array}$ \\
\hline 9 & $10,990.30$ & 0.131 & $10,622.62$ & 0.126 \\
\hline 11 & $11,186.27$ & 0.133 & $10,834.11$ & 0.129 \\
\hline 13 & $11,294.92$ & 0.134 & $10,989.33$ & 0.131 \\
\hline 15 & $11,508.35$ & 0.137 & $11,178.51$ & 0.133 \\
\hline 17 & $11,774.16$ & 0.140 & $11,341.49$ & 0.135 \\
\hline 19 & $12,069.08$ & 0.144 & $11,518.05$ & 0.137 \\
\hline
\end{tabular}

\subsection{Modelling results}

In this section we present the results of a numerical experiment carried out to evaluate the performance of a cross-docking terminal (small by international standards), employed by a supermarket organization in the distribution of freight to local stores. Since the main objective of the study 
has been to investigate the effects of different terminal settings and formulations, we have opted to generate some empirical data to test the model, as explained in Section 3.1.

The application of the methodology described in this research work has led to the following approximate characteristics of the analysed cross docking terminal:

- A total of 40 dock doors is proposed, distributed along both sides of the I-shaped facility (see Fig. 5);

- A total of 15 strip doors;

- A total of 23 destinations, with 25 stack doors, in which destinations 1 and 2 have two stack doors each;

- Stack doors layout and assignment as in indicated in Figure 5;

- Inbound vehicle unload scheduling is performed according to a LDFS queue discipline;

- Inbound trailers wait an average of 51 minutes to be unloaded (Table 3);

- The expected queue size of inbound trailers is 1.2 vehicles (Table 3);

- An internal terminal area of about 2,992 square meters is necessary;

- Use electric pallet trucks to move freight inside the terminal;

- Total expected cost of BRL\$ 0.253 per carton.

In Table 8 and Figure 12 it is shown the total cost per carton as a function of the number of strip doors, and considering the two alternative queue disciplines FCFS and LDFS. The two alternative freight handling alternatives are also analysed. In Figure 11 one can see that the queue length for the LDFS discipline is smaller than in the FCFS alternative, because the trailer scheduling process is better organized in the latter discipline, but the waiting time comparatively increases, as expected when compared to the classic discipline FCFS.

For the four-wheel dollies, the best solution is to assign 15 strip doors associated with the FCFS queueing discipline. When adopting the electric pallet trucks, the best solution is also 15 strip doors, but with the LDFS discipline. However, although the analysed cross-docking terminal is seen as a small facility by international terms, the unit cost of the pallet truck version is much lower than the manual solution. In fact, the four-wheel dolly best alternative costs about BRL\$ 0.41 per carton, while the pallet truck version costs about BRL\$ 0.25 per carton, a value about $39 \%$ smaller.

Table 8 and Figure 12 show that the employment of pallet trucks to carry freight in the terminal shows a much smaller cost than the four-wheeled platform dolly alternative. But, with regard to the use of either the FCFS or the LDFS queuing disciplines, Table 8 and Figure 12 show that both disciplines present approximately the same cost in this application. Apart from the factors 
Table 8 - Expected cost per carton.

\begin{tabular}{|c|c|c|c|c|}
\hline $\begin{array}{c}\text { Number of } \\
\text { strip doors }\end{array}$ & \multicolumn{2}{|c|}{$\begin{array}{c}\text { Internal transport with } \\
\text { four-wheel platform dollies }\end{array}$} & \multicolumn{2}{|c|}{$\begin{array}{c}\text { Internal transport with } \\
\text { electric pallet trucks }\end{array}$} \\
\hline$m_{1}$ & $\begin{array}{c}F C F S \text { queue } \\
\text { discipline } \\
\text { (BRL\$/carton) }\end{array}$ & $\begin{array}{c}\text { LDFS queue } \\
\text { discipline } \\
\text { (BRL\$/carton) }\end{array}$ & $\begin{array}{c}F C F S \text { queue } \\
\text { discipline } \\
\text { (BRL\$/carton) }\end{array}$ & $\begin{array}{c}\text { LDFS queue } \\
\text { discipline } \\
\text { (BRL\$/carton) }\end{array}$ \\
\hline 9 & 0.441 & 0.444 & 0.276 & 0.275 \\
\hline 11 & 0.425 & 0.427 & 0.262 & 0.261 \\
\hline 13 & 0.418 & 0.419 & 0.256 & 0.254 \\
\hline 15 & 0.413 & 0.416 & 0.253 & 0.253 \\
\hline 17 & 0.413 & 0.416 & 0.255 & 0.255 \\
\hline 19 & 0.415 & 0.417 & 0.261 & 0.257 \\
\hline
\end{tabular}

discussed in Section 3.1, the advantage of employing the LDFS discipline increases with terminal size. In fact, the configuration analysed here is related to a small facility. As long as the number of dock doors increases to adjust to the growing demand, the average distance between strip doors and stack doors increases accordingly, and the cost of internally moving freight tends to grow significantly. Thus, if the terminal freight movement tends to grow in the future, the facility will probably be enlarged at some point of time, and demanding for a LDFS orientation. So, an earlier adoption of such discipline can be tried out by the workers and management, letting it to be adapted to the company needs over a somewhat longer period of time, with positive benefits. So, the LDFS discipline seems to be better than the FCFS one.
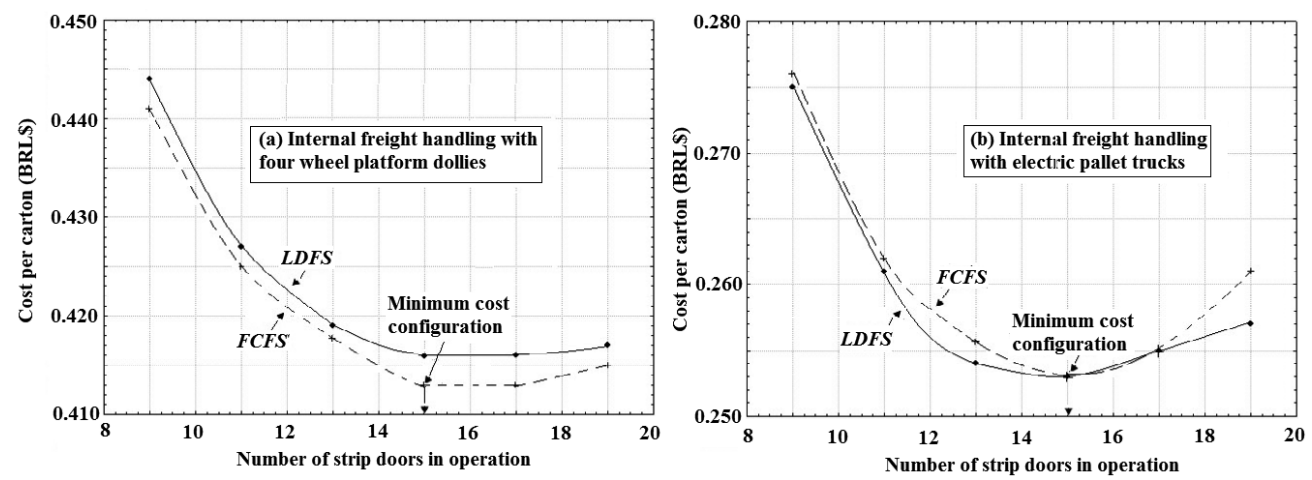

Figure 12 - Cost per carton as a function of the number of strip doors.

\section{CONCLUSIONS AND RESEARCH PROSPECTS}

The methodological structure developed in this paper involves a number of analytic approaches intended to produce elements to help in the design of a cross docking terminal. Of course, the methodology is not universal, since different terminal problem settings will require adaptations and further developments in some specific parts of the model. But one important and positive 
result of this work is that some parts of the problem, normally considered cumbersome in terms of mathematical treatment as, for example, queueing analysis, door assignment, and truck scheduling, can be treated in a robust and simple modelling way, with reasonable results, as shown in the present paper.

Some aspects of the problem will receive special attention in our future research efforts. First, the time window of 8 hours set up to receive freight at the terminal can be split into shorter time-windows, establishing, for example, four periods of two hours each. Such a measure would help in improving arrival reliability, and also leading to less strip doors and smaller facility areas, with reduced costs, but it would require more integration among the terminal organization, the suppliers, and the transport operators.

Regarding the use of simulation to solve this type of problem, the available commercial software, as Arena and others, provide simple evaluations such as in this application, in which the number of split doors constitutes the basic decision variable. But simple evaluations may not provide enough details for optimal decision making. One alternative is to combine simulation with optimization techniques to get better performance evaluations. For example, the Arena optimization module OptQuest allows to model and experiment with several alternative scenarios, letting the researcher to select the one that best meets the problem objectives. Thus, one research development to follow further will be to enlarge and detail the simulation framework of the problem, employing OptQuest-likely optimization search technologies in order to exploit better solutions.

Another point to investigate further is to focus on the benefits of anticipating the labelling and addressing of freight units to vendor premises, which will reduce freight handling and facility space at the terminal, with positive impacts in cost reduction. This, of course, will depend on specific arrangements with suppliers. Another research possibility is to introduce the congestion effects in terminal performance and costs, due to different types of internal traffic conflicts, as reported by Bartholdi \& Gue (2000).

\section{ACKNOWLEDGMENTS}

This research has been supported by $\mathrm{CNPq}$ - The Brazilian Council of Technological and Scientific Development, projects numbers 302527/2011-7 and 470899/2013-1.

\section{REFERENCES}

[1] ACAR K, YAlcin A \& YAnKov D. 2012. Robust door assignment in less-than truckload terminals. Computers \& Industrial Engineering, 63: 729-738.

[2] Agustina D, Lee CKM \& Piplani R. 2010. A review: Mathematical models for cross docking planning. International Journal of Engineering Business Management, 2(2): 47-54.

[3] Agustina D, Lee CKM \& Piplani R. 2014. Vehicle scheduling and routing at a cross docking center for food supply chains. Int. J. Production Economics, 152: 29-41.

[4] Alpan G, LARbi R \& Penz B. 2011. A bounded dynamic programming approach to schedule operations in a cross docking platform. Computers \& Industrial Engineering, 60: 385-396. 
[5] Amini A, Tavak koli-Moghaddam R \& Omidvar A. 2014. Cross-docking truck scheduling with the arrival times for inbound trucks and the learning effect of unloading/loading processes. Production \& Manufacturing Research: An Open Access Journal, 2(1): 784-804.

[6] Amini A \& Tavaknoli-Moghaddam R. 2016. A bi-objective truck scheduling problem in a cross-docking center with probability of breakdown for trucks. Computers \& Industrial Engineering, 96: 180-191.

[7] Apte UM \& Viswathan S. 2000. Effective cross docking for improving distribution efficiencies, International Journal of Logistics: Research and Applications, 3(3): 291-302.

[8] BARTHOLDi JJ \& GUE KR. 2000. Reducing labor costs in a LTL crossdocking terminal. Operations Research, 48(6): 823-832.

[9] Bartholdi JJ \& Gue KR. 2004. The best shape of a cross dock. Transportation Science, 38(2): 235-244.

[10] Bartholdi JJ \& Hackman ST. 2014. Warehouse and Distribution Science - Release 0.96. The Supply Chain and Logistics Institute, Georgia Institute of Technology, Atlanta, GA, USA.

[11] Berghman L \& LeUS R. 2015. Practical solutions for a dock assignment problem with trailer transportation. European Journal of Operational Research, 246: 787-799.

[12] BOZER YA \& CARLO HJ. 2008. Optimizing inbound and outbound door assignments in less-thantruckload crossdocks. IEE Transactions, 40(11): 1007-1018.

[13] Boyd Co. 2013. The cost of operating a distribution centre, Tucson - New Boyd Study $<$ www.werc.org/assets/1/Publications/950\%20BoydTucson.pdf>, March, 2013.

[14] Boysen N \& FLiedner M. 2010. Cross dock scheduling: Classification, literature review and research agenda, Omega, 38: 413-422.

[15] Boysen N, Fliedner M \& Scholl A. 2010. Scheduling inbound and outbound trucks at cross docking terminals. OR Spectrum, 32: 135-161.

[16] Buijs P, Vis IFA \& CARLo HJ. 2014. Synchronization in cross-docking networks: A research classification and framework. European Journal of Operational Research, 239(3): 593-608.

[17] Cohen Y \& KeREN B. 2009. Trailer to door assignment in a synchronous cross-dock operation. International Journal of Logistics Systems and Management, 5(5): 574-590.

[18] Deshpande P, Yalcin A, Zayas-Castro J \& Herrera E. 2007. Simulating less-than-truckload terminal operations. Benchmarking: An International Journal, 14(1): 92-101.

[19] Gelareth S, Monemi RN, Semet F \& Goncalves G. 2016. A branch-and-cut algorithm for the truck door assignment problem with operational time constraints. European Journal of Operational Research, 249: 1144-1152.

[20] Gerald CF \& Wheatley PO. 2004. Applied Numerical Analysis (7th Edition), Addison-Wesley, Boston, Mass, USA.

[21] Gross D, Shortle JF, Thompson JM \& HARris CM. 2008. Fundamentals of Queueing Theory (4th Edition), John Wiley \& Sons, New York, NY, USA.

[22] GUE KR. 1999. The effects of trailer scheduling on the layout of freight terminals. Transportation Science, 33(4): 419-428. 
[23] Fogliati MC \& Mattos NMC. 2007. Teoria de Filas. Editora Interciência, Rio de Janeiro, Brazil.

[24] Kelton WD, Sadowski R \& Zupick N. 2014. Simulation with Arena (6th Edition), WCB/ McGraw-Hill.

[25] Konur D \& Golias MM. 2013. Analysis of different approaches to cross-dock scheduling with truck arrival time uncertainty. Computers \& Industrial Engineering, 65: 663-672.

[26] LitTLE JDC. 1961. A Proof of the queuing formula $L=\lambda W$. Operations Research, 9(3): 383-387.

[27] Little JDC \& Graves SS. 2008. Little's Law in: Chhajed D \& Lowe TJ (eds.) Building Intuition: Insights from Basic Operations Management Models and Principles, Springer Science + Business Media, LLC, New York, USA.

[28] LIU Y \& TAKAKURA S. 2010. Enhancing simulation as a decision-making support tool for a crosscenter in a dynamic retail-distribution environment in: JoHANSSON B, JAIN S, MONTOYA-TORRES J, Hugan J \& YÜCESAn E (eds.), Proceedings of the 2010 IEEE Winter Simulation Conference, December 5-8, 2010, Baltimore, USA.

[29] MAKNOON MY \& BAPTiste P. 2009. Cross-docking: Increasing platform efficiency by sequencing incoming and outgoing semi-trailers. International Journal of Logistics Research and Applications, 12(4): 249-261.

[30] MCWilliams DL, Stanfield PM \& Geiger CD. 2005. The parcel hub scheduling problem: A simulation-based approach. Computers \& Industrial Engineering, 49: 393-412.

[31] Miao Z, Lim A \& MA H. 2009. Truck dock assignment problem with operational time constraint within cross docks. European Journal of Operational Research, 192: 105-115.

[32] Miao Z, CAI S \& XU D. 2014. Applying an adaptive tabu search algorithm to optimize truck-door assignment in the cross dock management system. Expert Systems with Applications, 41: 16-22.

[33] Newell GF. 1971. Applications of Queueing Theory, Chapman and Hall, London, UK.

[34] Odoni AR \& De Neufville R. 1992. Passenger terminal design. Transportation Research - A, 26-A(1): 27-35.

[35] PAge E. 1972. Queueing Theory in OR. Butterworths, London, UK.

[36] PRABhU NU. 1965. Queues and Inventories. John Wiley \& Sons, London, UK.

[37] Reimann M, Tavares Neto R \& Bogendorfer E. 2014. Joint optimization of production planning and vehicle routing problems: A review of existing strategies. Pesquisa Operacional, 34(2): 189-214.

[38] Rouwenhorst B, Reuter B, Stockrahn V, van Houton GJ, Mantel RJ \& Zijm WhM. 2000. Warehouse design and control: Framework and literature review, European Journal of Operational Research, 122: 515-533.

[39] Rubinstein RY \& Kroese DP. 2017. Simulation and the Monte Carlo Method (3rd Edition). John Wiley \& Sons, Hoboken, NJ, USA.

[40] SADYKOV R. 2009. A polynomial algorithm for a simple scheduling problem at cross docking terminals, Research Report RR-7054, IMB - Institut de Mathmatiques de Bordeaux, Inria, France.

[41] Shakeri M, Low MYH, Turner SJ \& LeE EW. 2012. A robust two-phase heuristic algorithm for the truck scheduling problem in a resource-constrained crossdock. Computers \& Operations Research, 39: 2564-2577. 
[42] Shi W, Liu Z, Shang J \& Cui Y. 2013. Multi-criteria robust design of a JIT - based cross-docking distribution center for an auto parts supply chain. European Journal of Operational Research, 229: 695-706.

[43] Stephan K \& Boysen N. 2011. Cross-docking, Journal of Management Control, 22: 129-137.

[44] Takakuwa S, Takizawa H, Ito K \& Hiraoka S. 2010. Simulation and analysis of nonautomated distribution warehouses. Proceedings of the 2000 Winter Simulation Conference, 10-13 Dec., Orlando, FL, USA.

[45] Tsui LY \& Chang CH. 1992. An optimal door solution to a dock door assignment problem. Computers \& Industrial Engineering, 23(1-4): 283-286.

[46] Vahdani B, Soltani R \& Zandieth M. 2010. Scheduling truck holdover recurrent dock crossdock problem using robust meta-heuristics. International Journal of Advanced Manufacturing Technology, 46: 769-783.

[47] Van Belle J, Valckenaers P \& Cattrysse D. 2012. Cross-docking: State of the art. Omega, 40: $827-846$.

[48] Van Belle J, Valckenaers P, Berghe GV \& Cattrysse D. 2013. A tabu search approach to the truck scheduling problem with multiple docks and time windows. Computers \& Industrial Engineering, 66: 818-826.

[49] VIEIRA CLS \& LUNA MMM. 2016. Models and methods for logistics hub location: A review towards transportation networks design. Pesquisa Operacional, 36(2): 375-397.

[50] Vis FA \& Roodbergen KJ. 2011. Layout and control policies for cross docking operations. Computers \& Industrial Engineering, 61: 911-919.

[51] WANG JF \& REgAn A. 2009. Real-time trailer scheduling for crossdock operations. Trasnportation Journal, 47(2): 5-20.

[52] Worthington D. 2009. Reflections on queue modelling from the last 50 years. Journal of the Operational Research Society, 60: S83-S92.

[53] YU W \& Egbelu PJ. 2008. Scheduling inbound and outbound trucks in cross docking systems with temporary storage. European Journal of Operational Research, 184: 377-396. 